\title{
Geç Kretase Yaşlı Bozat (Giresun, KD Türkiye) Plütonu'nun Petrografik, Jeokimyasal ve Petrolojik Özellikleri
}

\author{
Petrographical, Geochemical and Perological Characteristics of Late Cretaceous aged \\ Bozat (Giresun, NE Turkey) Pluton
}

\author{
İrfan TEMIZEL ${ }^{*, a}$, Ayșe KURT ${ }^{\mathrm{b}}$ \\ Karadeniz Teknik Üniversitesi, Mühendislik Fakültesi, Jeoloji Mühendisliği Bölümü, 61080, Trabzon
}

• Geliş tarihi / Received: 09.01.2019 • Düzeltilerek geliş tarihi / Received in revised form: 27.02.2019 • Kabul tarihi / Accepted: 05.03.2019

\begin{abstract}
$\ddot{O} z$
Doğu Pontidler Orojenik Kuşağı'nda (KD Türkiye) farklı boyut ve bileşimlerde olan Geç Kretase yaşlı plütonlar yaygın olarak yüzeylenmektedir. Bunlardan Bozat Plütonu (Giresun) yaklaşık KD-GB uzanımlı olup, Üst Kretase volkanik ve sedimanter kayaçları içerisine yerleşmiştir. Petrografik olarak, incelenen plüton ince-orta taneli olup, monzogabro bileşimlidir. Plüton kayaçları, genel olarak plajiyoklas $\left(\mathrm{An}_{53-88}\right)$, ortoklas $\left(\mathrm{Or}_{59-74}\right)$, kuvars, klinopiroksen $\left(\mathrm{Wo}_{40-45} \mathrm{En}_{42-}\right.$ ${ }_{44} \mathrm{Fs}_{12-17}$ ), biyotit (Mg\#: 0.66-0.70), Fe-Ti oksit, apatit ve zirkon içermekte olup, genellikle monzonitik, poikilitik, nadiren pertitik doku gösterirler. Petrokimyasal olarak, incelenen plüton I-tipi, metalümin $(\mathrm{A} / \mathrm{CNK}=0.76-0.93)$ ve şoşonitik karakterdedir. Ana ve iz element verileri, incelenen plütonun gelişiminde fraksiyonel kristallenme \pm asimilasyonun önemli bir rol oynadığına işaret etmektedir. İncelenen plütonun ilksel mantoya normalize edilmiş iz element dağılımları, büyük iyon yarıçaplı litofil element, Th, Ce zenginleşmesi ve negative $\mathrm{Nb}$, Ta ve Ti anomalisi göstermekte olup, bu kayaçların petrojenezinde yitim bileşeninin etkili olduğunu göstermektedir. Ayrıca, incelenen plüton kayaçlarının kondrite normalize edilmiş nadir toprak element dağıllımlarında karakteristik olarak gözlenen konkav şekilli desen ve negatif Eu anomalisi, gelişiminde K-feldispat \pm plajiyoklas ve klinopiroksen ayrımlaşmasının etkili olduğuna işaret etmektedir. Elde edilen tüm veriler, Geç Kretase yaşlı Bozat Plütonu'nun gerilmeli kıtasal yay ortamında oluştuğunu ve ana magmasının litosferik manto ve alt kabuktan türeyen ergiyiklerin karışımından türediğini ve kabuk içerisindeki magma odasında farklılaşarak yerleştiğini işaret etmektedir.
\end{abstract}

Anahtar kelimeler: Bozat, Jeokimya, Mineral kimyası, Monzogabro, Giresun, Türkiye

\begin{abstract}
Late Cretaceous aged intrusions in the Eastern Pontides Orogenic Belt in NE Turkey are common in varying sizes and compositions. Of these, Bozat Pluton (Giresun) extends nearly in the orientation of NE-SW and was emplaced into the Upper Cretaceous volcanic and sedimentary rocks. Petrographically, the studied pluton is compositionally fine to medium grained monzogabbro. The rocks of the pluton consist of plagioclase $\left(\mathrm{An}_{53-88}\right)$, orthoclase $\left(\mathrm{Or}_{59-74}\right)$, quartz, clinopyroxene (Wo $\left.{ }_{40-45} E_{42-44} F_{12-17}\right)$, biotite (Mg\#: 0.66-0.70), Fe-Ti oxide, apatite and zircon with generally monzonitic, poikilitic, rare perthitic textures. Petrochemically, the studied pluton shows I-type, metaluminous $(\mathrm{A} / \mathrm{CNK}=0.76-0.93)$ and shoshonitic features. The major and trace element data suggest that fractionational crystallization \pm assimilation has played a significant role in the evolution of the studied pluton. Primitive mantlenormalized trace element patterns of rocks samples from the pluton exhibit enrichment in large ion lithophile element, $\mathrm{Th}, \mathrm{Ce}$ and negative Nb, Ta and Ti anomalies, all of which suggest subduction component in their petrogenesis. Moreover, chondrite-normalized rare earth element (REE) plots of rocks from the pluton show characteristic concaveshaped patterns with negative Eu anomalies, all of which imply significant $K$-feldspar \pm plagioclase and clinopyroxene fractionations in evolution of the pluton. All obtained data suggest that the Late Cretaceous aged Bozat Pluton has formed in an extensional continental arc, and parental magma of the pluton evolved from mixing of lithospheric mantle and lower crust-derived melts, and evolved differently within crustal level.
\end{abstract}

Keywords: Bozat, Geochemistry, Mineral chemistry, Monzogabbro, Giresun, Turkey

\footnotetext{
*a İrfan TEMIZEL; itemizel@ktu.edu.tr; Tel: (0462) 377 27 41; orcid.org/0000-0002-6293-8649

${ }^{\mathrm{b}}$ orcid.org/0000-0003-2981-8335
} 


\section{Giriş}

Doğu Pontidler Orojenik Kuşağı (DPOK)'nda Paleozoyik'den Tersiyer dönemi sonuna kadar geniş bir yaş aralığında gözlenen plütonlar; gabrodan granite kadar değişen bileşimde olup, başlıca Permo-Karbonifer, Erken-Orta Jura, Geç Kretase ve Eosen döneminde sokulum yapmışlardır (Şekil 1). Permo-Karbonifer yaşlı granitoyidler (Örn, Topuz vd., 2010; Dokuz, 2011; Kaygusuz vd., 2012, 2016) metamorfik kayaçları keserek yerleşmiştir. Bu granitoyidler, Gümüşhane, Köse ve Artvin civarında (Örn, Topuz vd., 2010; Dokuz, 2011), Tonya güneyinde, Maçka güneyinde (Soğuksu) ve Özdil (Trabzon) yöresinde (Kaygusuz vd., 2012, 2016) gözlenmektedir. Ayrıca, metamorfik temel kayaçlar, mafik ve daha az oranda felsik kayalardan oluşan Erken Jura granitoyidleri tarafından da kesilmiştir (Dokuz vd., 2010; Ustaömer vd., 2013; Karsl1 vd., 2017; Dokuz vd., 2017) (Şekil 1). Geç Kretase granitoyidleri, yitimle ilişkili volkanik ve/veya volkanoklastik kayaçlarla dokanak ilişkisindedir (Yılmaz ve Boztuğ, 1996; Karsl1 vd., 2010; Kaygusuz vd., 2008, 2009, 2010, 2011, 2012; Kaygusuz ve Aydınçakır, 2009, 2011; Kaygusuz ve Şen, 2011; Karsl1 vd., 2012a; Kaygusuz vd., 2013, 2014; Sipahi vd., 2018). Eosen ve sonrası granitoyidleri ise dar alanlarda yüzeylemekte olup, tüm serileri keserek yerleşmiştir (Y1lmaz ve Boztuğ, 1996; Aslan vd., 1999; Topuz, 2002; Arslan ve Aslan, 2006; Karslı vd., 2007; 2011, 2012b; Temizel, 2014; Kaygusuz ve Öztürk, 2015; Sipahi vd., 2017; Temizel vd., 2018; Şekil 1).

DPOK'nın doğusunda Geç Kretase yaşlı bazı plütonların petrografisini, jeokimyasını ve petrojenezini içeren birçok çalışma yapılmıştır (ör., Y1lmaz ve Boztuğ, 1996; Karsl1 vd., 2010; Kaygusuz vd., 2008, 2009, 2010, 2011, 2012; Kaygusuz ve Aydınçakır, 2009, 2011; Kaygusuz ve Şen, 2011; Karsl1 vd., 2012a; Kaygusuz vd., 2013, 2014; Sipahi vd., 2018). Bölgede gözlenen Geç Kretase yaşlı plütonik kayaçların yaşları ile ilgili yapılan radyometrik çalışmalar belirtildiği gibi bazı plütonlarda ve sinırlı alanlardadır. Genel olarak plütonların yaşı stratigrafik ilişkilerle göreceli olarak saptanmaya çalışılmıştır. Ayrıca, bölgenin batısındaki Bozat (Piraziz, Giresun) yöresi ve çevresinde yer alan Geç Kretase yaşlı plütonlarla ilgili detaylı petrografik, jeokimyasal ve petrolojik çalışma bulunmamaktadır. $\mathrm{Bu}$ çalışmada, Piraziz (Giresun) güneydoğusunda Bozat beldesinde yüzeyleme veren, Geç Kretase yaşlı Bozat plütonunun detaylı petrografik ve mineral kimyası özelliklerinin belirlenmesi, jeokimyasal ve petrolojik özelliklerinin ortaya konulması ve tektonik ortamları hakkında literatüre katkı sağlanması amaçlanmıştır.

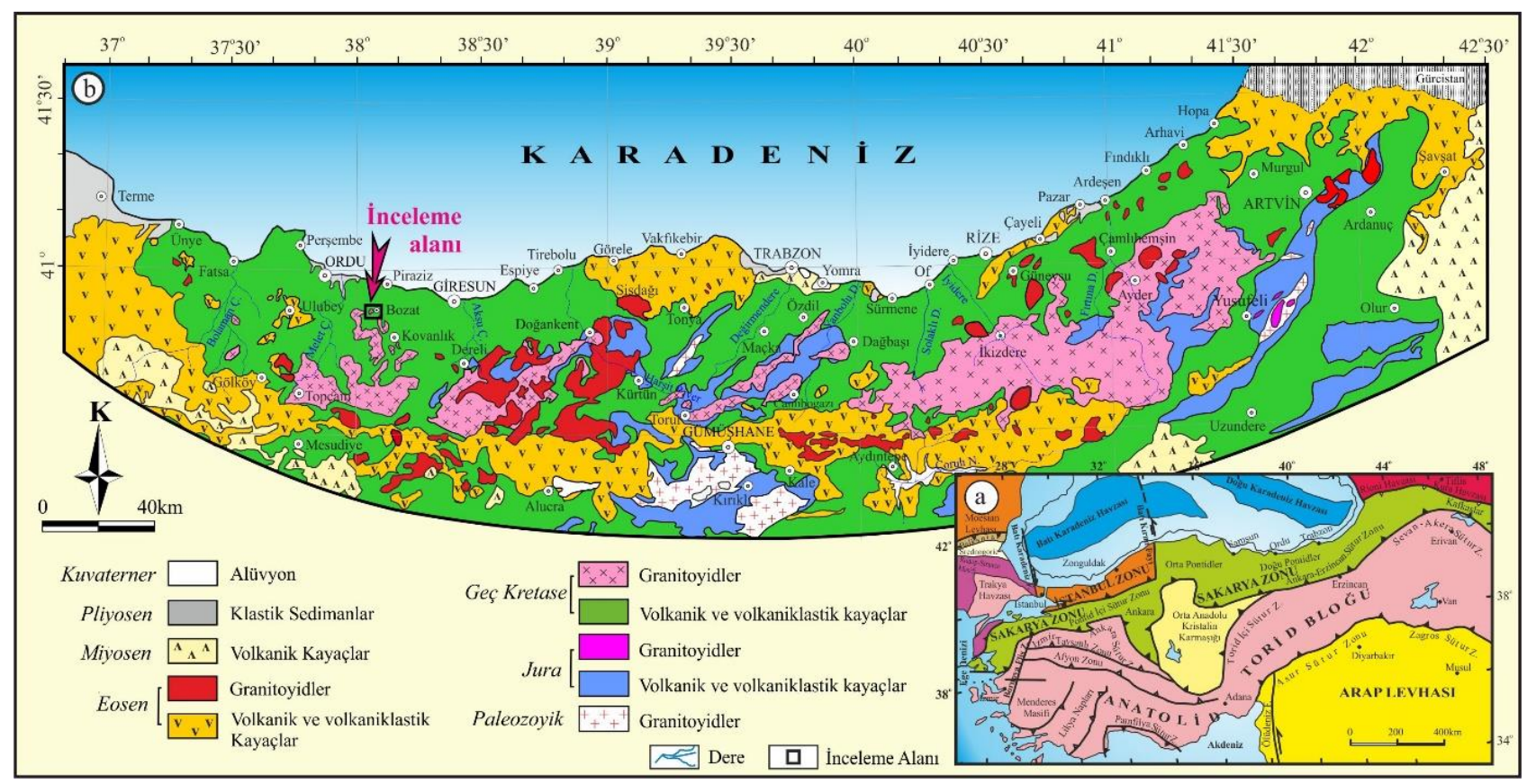

Şekil 1. a) Türkiye'nin tektonik haritası (Okay ve Tüysüz, 1999'dan değiştirilerek), (b) Doğu Pontidler'deki plütonik kayaçların dağılımını gösteren jeoloji haritası (Güven, 1993; MTA, 2002; Arslan vd., 2013; Temizel vd., 2016; Yücel vd., 2017'den değiştirilerek). 


\section{Jeolojik Konum ve Bozat Plütonunun Saha Özellikleri}

DPOK'de Giresun İli Bozat İlçesinde yer alan ve genelde volkanik, plütonik ve tortul kayaçların egemen olduğu çalışma alanının temelini; Turoniyen-Koniasiyen-Santoniyen (Geç Kretase) yaşlı Çatak Formasyonu (Güven, 1993)'na ait bazalt, andezit ve piroklastitleri ile kumtaş1, silttaşı, marn, şeyl ve mikritik kireçtaşı araseviyeleri oluşturur (Şekil 2). Bu birim, Santoniyen (Geç Kretase) yaşlı riyolit, dasit ve piroklastitleri ile kumtaşı ve kırmızı renkli killi kireçtaşlarından oluşan Kızılkaya Formasyonu (Güven, 1993) tarafindan uyumlu olarak üzerlenmektedir (Şekil 2). Kızılkaya Formasyonu üzerine uyumlu olarak Santoniyen-Kampaniyen (Geç Kretase) yaşlı andezit, bazalt ve piroklastitleri ile kumtaşı, marn ve killi kireçtaşı araseviyelerinden oluşan Çağlayan Formasyonu
(Güven, 1993) gelmektedir (Şekil 2). Bu birim üzerine uyumlu olarak Kampaniyen-Maastrihtiyen (Geç Kretase) yaşlı riyolit, dasit ve piroklastitleri ile kumtaşı ve killi kireçtaş1 araseviyelerinden oluşan Tirebolu Formasyonu (Güven, 1993) gelmektedir (Şekil 2).

İncelenen Bozat plütonu, yaklaşık $15 \mathrm{~km}^{2}$ 'lik bir alanda Giresun İli, Piraziz İlçesi, Bozat Beldesi güneybatısında Hatipoğlu, Köydüzü, Kozçukuru ve çevresinde, özellikle de Zekere Dere, Kavaklıdağ Dere, Bullan Dere ve Karagürgen Dere boyunca yüzeyleme vermektedir (Şekil 2). Bozat Plütonu, Turoniyen-Koniasiyen-Santoniyen yaşlı Çatak Formasyonu'nu, Santoniyen yaşlı Kizılkaya Formasyonu, Santoniyen-Kampaniyen yaşlı Çağlayan Formasyonu ve KampaniyenMaastrihtiyen yaşlı Tirebolu Formasyonu'na ait volkanik ve volkano-tortul kayaçlarını keserek yerleşmiştir (Şekil 2).

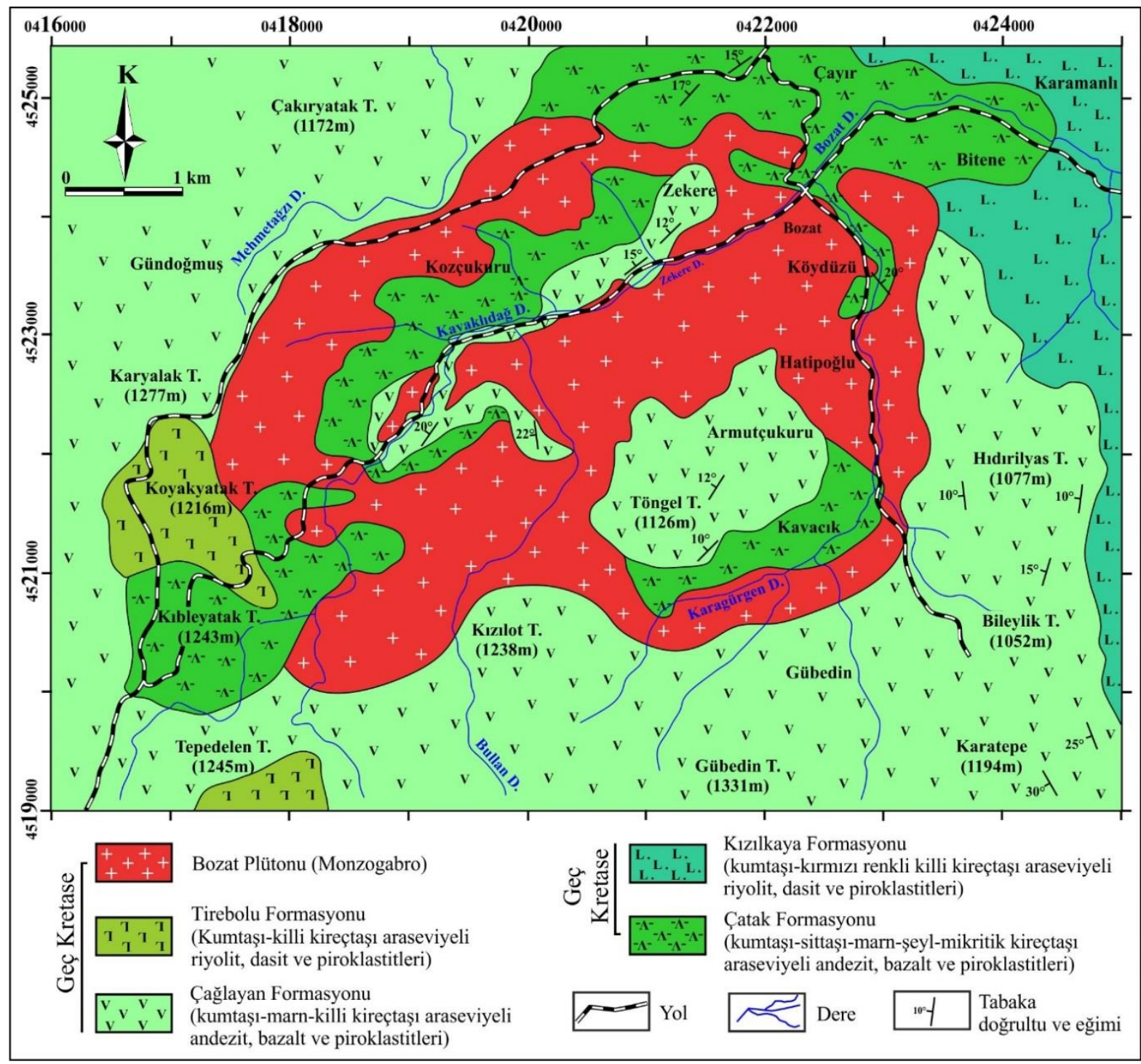

Şekil 2. Bozat Plütonu ile çevre kayaçlarını gösteren jeoloji haritası (Güven, 1993; MTA, 2002'den değiştirilerek). 
Saha gözlemleri, dokanak ve yan kayaç ilişkilerine göre plütonun yaşı Geç Kretase olarak kabul edilmektedir (Güven, 1993). Plütonun uzun ekseni kuzeydoğu-güneybatı istikametinde uzanım göstermekte olup, genelde elips şekillidir (Şekil 2). Genel olarak oldukça sert, çatlaklı ve kırıklı yapı sunarlar ve küçük bloklar şeklinde yüzeyleme vermektedirler (Şekil 3a, b). Sahada renkleri genellikle gri-koyu ve sarımsi gri olup ve orta-ince tanelidirler (Şekil 3a, b). Plütonun yan kayaç ile olan dokanak zonlarında az oranda silisleşme ve epidotlaşma gözlenmiştir.
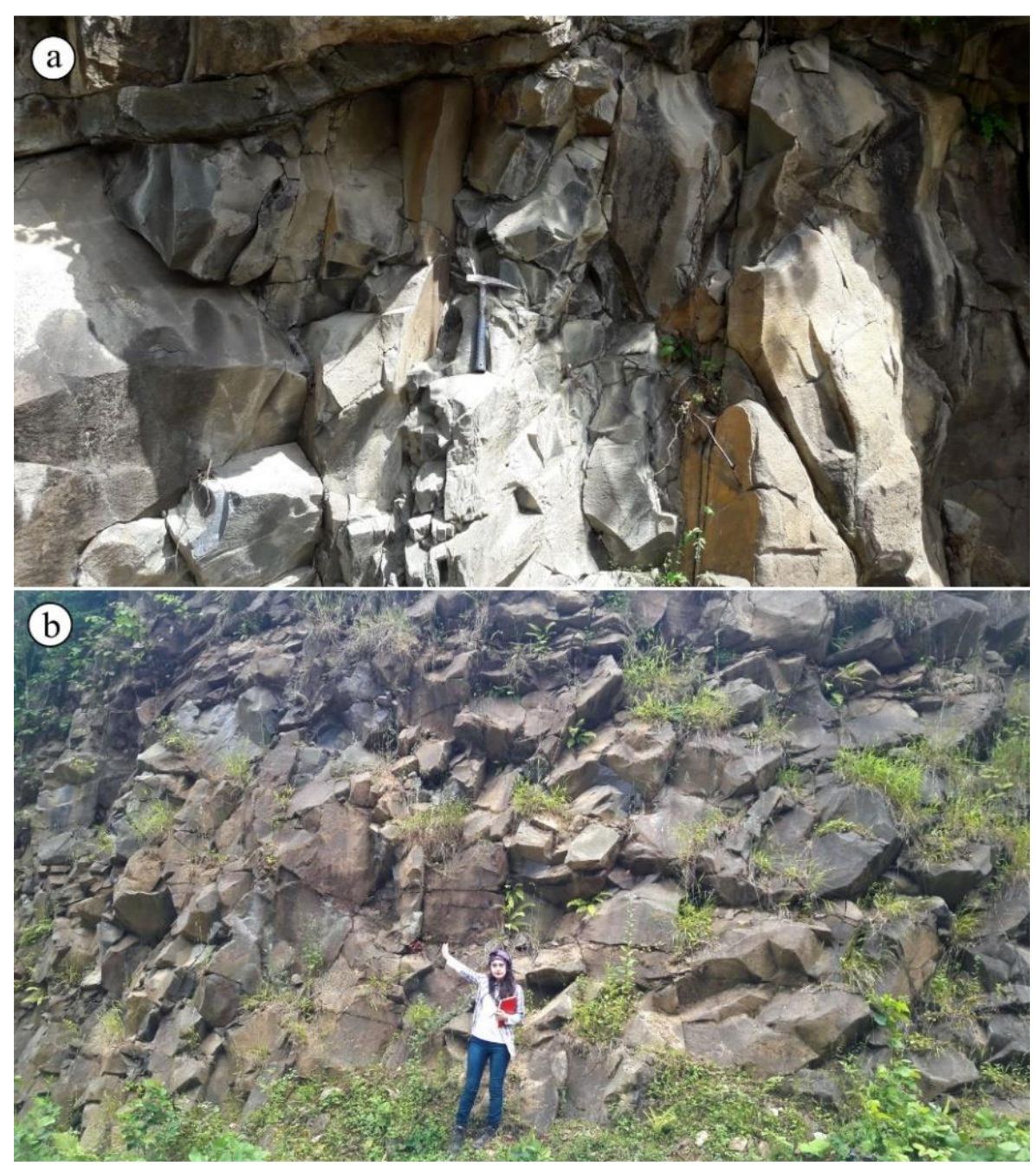

Şekil 3. Bozat Plütonu'na ait bol çatlaklı ve kırıklı yapıya sahip, ince-orta taneli monzogabroların arazi görünümü $(\mathbf{a}, \mathbf{b})$.

\section{Analitik Metod}

Saha çalışmalarında öncel jeolojik haritalardan (Güven, 1993; MTA, 2002) faydalanılarak yörenin 1/25000 ölçekli detay jeolojik haritası revize edilmiş ve incelenen Bozat Plütondan petrografik ve jeokimyasal amaçlı kayaç örnekleri alınmıştır.

Kayaç incekesitleri, Karadeniz Teknik Üniversitesi Mühendislik Fakültesi Jeoloji Mühendisliği Bölümü İncekesit Laboratuarı'nda hazırlanmıştır. İncekesitler polarizan mikroskopta incelenmiş, kayaçların mineralojik bileşimleri, dokusal-petrografik özellikleri ayrıntılı olarak irdelenmiştir. Modal analiz için Swift nokta sayacı kullanılmıştır. Sayım genellikle $0.4 \mathrm{~mm}$ aralığı, tane boyutuna göre bazen de $0.2 \mathrm{~mm}$ aralığında gerçekleştirilmiş ve her bir kesitte yaklaşık 400500 nokta sayılmıştır.

Mineral kimyası analizleri Universite de Bretagne Occidentale (Brest, Fransa) Geoscience Marines (IFREMER) Elektron Mikroprob Laboratuarı'nda yapılmıştır. Karbon kaplı parlak kesitler üzerindeki mineral kimyası çalışmaları, CAMECA-SX-100 WDS marka bir elektron mikroprob aleti ile gerçekleştirilmiştir. Aletin 
çalışma şartları $15 \mathrm{kV}$ voltaj ve $20 \mathrm{nA}$ 'dır. Analizler $10 \mu \mathrm{m}$ 'lik bir ışın çapında yapılmış ve $\mathrm{Si}, \mathrm{Al}, \mathrm{Ti}, \mathrm{Fe}, \mathrm{Mn}, \mathrm{Mg}, \mathrm{Ca}, \mathrm{Na}$ ve $\mathrm{K}$ elementleri için sayılma zamanı 10 sn olarak belirlenmiştir. 1 $\mu$ m'lik bir nokta 1şını piroksen, hornblend ve FeTi oksit analizleri için kullanılmıştır. Feldispat ve mika analizlerinde sodyum buharlaşması nedeniyle oluşacak kayıpları önlemek için çok hafif defokuslamış $(10 \mu \mathrm{m})$ 1şın kullanılmıştır. Analizlerdeki doğal mineral standartları forsterit, diyopsit, ortoklas, albit, anortit, biyotit, apatit, vollastonit ve magnetittir. Analitik hata ana elementler için \%1'den ve iz elementler için ise 200 ppm den daha azdır.

Petrografik incelemeler sonucuna göre incelenen plütondan seçilen ayrışmamış ve taze kayaç örnekleri Karadeniz Teknik Üniversitesi Mühendislik Fakültesi Jeoloji Mühendisliği Bölümü Örnek Hazırlama ve Öğütme Laboratuarı'nda önce çelik çeneli kırıcı ile kırılmıştır. Daha sonra çelik halkalı öğütücü içinde yaklaşık 200 mesh boyutuna kadar öğütülerek toz haline getirilmiştir.

Plütonlara ait kayaç tozlarından itibaren tüm-kaya analizleri ACME Analitik Laboratuvarı'nda (Vancouver, Kanada) yaptırılmıştır. Ana ve iz element analizleri, 0.2 gr toz kayaç örneğinin 1.5 $\mathrm{gr} \mathrm{LiBO}_{2}$ ile çözdürülmesi ve daha sonra $100 \mathrm{ml}$ $\% 5 \mathrm{HNO}_{3}$ de çözülmesinden sonra indüksiyonlu eşleşmiş plazma atomik emisyon spektrometresi (ICP-AES) ile ölçülmüştür. Nadir toprak element (NTE) içerikleri 0.25 gr toz kayaç örneğinin dört farklı asit içerisinde çözdürülmesinden sonra indüksiyonlu eşleşmiş plazma kütle spektrometresi (ICP-MS) ile analiz edilmiştir. Ateşte kayıp (AK), örnekler $1000^{\circ} \mathrm{C}^{\prime} \mathrm{de}$ yakıldıktan sonra ağıllık farkından hesaplanmıştır. Toplam demir içeriği, $\mathrm{Fe}_{2} \mathrm{O}_{3}$ cinsinden ifade edilmiştir. Ana elementler \% ağırlık, iz ve nadir toprak elementler ise ppm olarak ölçülmüştür.

\section{Bulgular}

\subsection{Petrografi}

İncelenen plütona ait 12 adet örneğin modal analiz sonuçlarına (Tablo 1) göre, KAP (Kuvars-Alkali Feldispat-Plajiyoklas) diyagramında (Streickeisen, 1976) monzogabro/monzodiyorit alanına düşmektedir (Şekil 4). Plütonu oluşturan kayaçlar, genellikle monzonitik, poikilitik ve nadiren de pertitik doku gösterirler. Açık renkli mineraller plajiyoklas, ortoklas ve kuvars ile temsil edilirken, ferromagnezyen mineralleri klinopiroksen ve biyotit oluşturur (Şekil 5a-d). Plütona ait örneklerin bazılarında klinopiroksen fazlayken, biyotit mineralleri daha az orandadır. Bol olarak bulunan opak mineraller ile aksesuar mineral olarak gözlenen apatit ve zirkon diğer mineralleri oluşturur. Bazı örneklerde yer yer plajiyoklaslarda serisitleşme ve epidotlaşma, ortoklaslarda killeşme ve ferromagnezyen minerallerden itibaren kloritleşme izlenmiştir.

Tablo 1. Bozat Plütonu kayaçlarının genel petrografik özellikleri ile modal bileşimleri.

\begin{tabular}{llll}
\hline Plüton Adı & \multicolumn{3}{l}{ BOZAT PLÜTONU } \\
\hline $\begin{array}{l}\text { Kayaç Türü } \\
\text { Doku }\end{array}$ & $\begin{array}{l}\text { Monzogabro } \\
\text { Tane Boyu }\end{array}$ & $\begin{array}{l}\text { Monzonitik, poikilitik, pertitik } \\
\text { Orta-ince }\end{array}$ & \\
\hline Modal Min. (\%) & Ort. & Min. & Mak. \\
Plajiyoklas & 47.0 & 40.8 & 53.8 \\
Kuvars & 0.9 & 0.1 & 2.1 \\
Ortoklas & 21.7 & 20.1 & 22.7 \\
Piroksen & 19.8 & 13.1 & 25.4 \\
Biyotit & 3.9 & 1.5 & 5.7 \\
Tali Min. & 0.8 & 0.7 & 0.9 \\
Opak Min. & 3.4 & 2.3 & 4.3 \\
İkincil Min. & 2.7 & 1.5 & 3.6 \\
\hline
\end{tabular}

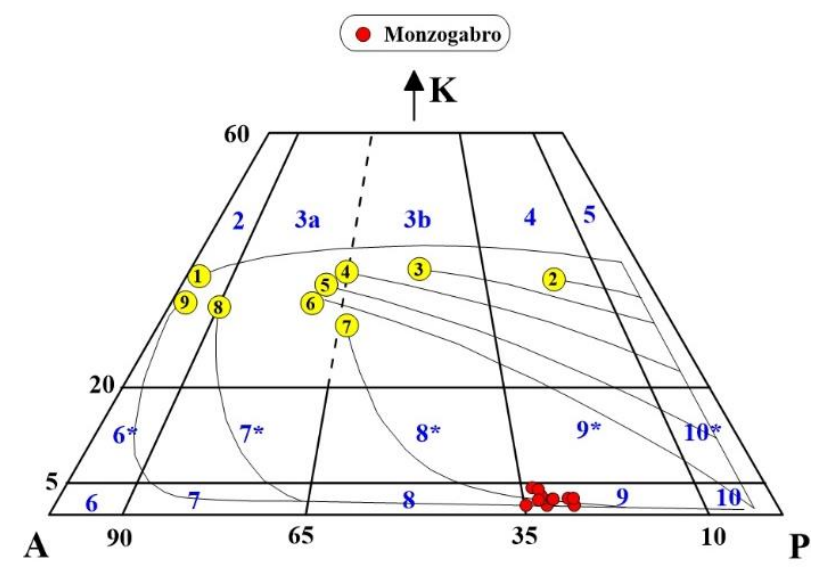

Şekil 4. Bozat Plütonu kayaçlarına ait K-A-P diyagramı. Eğriler; plütonik tip serilerinin yönlerini göstermekte olup; 1- toleyitik seriler, 2kalk-alkali trondjemitik seriler, 3-6- değişken kalka-alkali granodiyorit serileri, 7- monzonitik seriler, 8-9- değişken alkali seriler (Lameyre ve Bonin, 1991). Alanlar; (2) alkali feldispat granit, (3a) siyenogranit, (3b) monzogranit, (4) granodiyorit, (5) tonalit, $\left(6^{*}\right)$ kuvars alkali feldispat granit, $\left(7^{*}\right)$ kuvars siyenit, $\left(8^{*}\right)$ kuvars monzonit, $\left(9^{*}\right)$ kuvars monzodiyorit/ kuvars monzogabro, $(10 *)$ kuvars diyorit/ kuvars gabro/ kuvars anortozit, (6) alkali feldispat granit, (7) siyenit, (8) monzonit, (9) monzodiyorit/ monzogabro, (10) diyorit/ gabro/ anortozit (Streckeisen, 1976). 
Plajiyoklas (\% 41-54), kayaçta yaygın olarak öz ve yarı özşekilli, iri ve küçük prizmatik kristaller halinde gözlenmekte olup, genellikle albit polisentetik ikizlenmesi, nadiren karlsbad ikizi ve halkalı zonlanma gösterirler (Şekil 5a-d). Bazı kristallerde ikizlenme ve zonlanma birlikte görülür. Yalnızca zonlu yap1 gösteren plajiyoklaslarda büyüme düzensizlikleri mevcuttur. Ayrıca, özşekilli plajiyoklaslarda yer yer elek dokusu hâkimdir.

Ortoklas (\% 20-23), genelde özşekilsiz olup, hem iri ve hem de küçük kristaller halinde gözlenirler. Ortoklaslardan bazılarında karlsbad ikizlenmesi belirlenmiştir. Ayrıca, ortoklas içerisinde albit kusmaları ile karakteristik olan pertit oluşumları da saptanmıştır. Yer yer büyük ortoklas kristalleri, poikilitik olarak plajiyoklas, biyotit ve opak mineral kapanımları içerirler (Şekil 5a, c). Bazı kesitlerde ortoklas mineralleri plajiyoklasların etrafını kısmen çevreleyerek monzonitik dokuyu oluştururlar (Şekil 5b). Bazıları kırıklı ve kısmen killeşmiştir (Şekil 5d).

Kuvars (\% 1-3), özșekilsiz ve irili ufaklı kristaller halinde gözlenirler (Şekil 5b). Genel olarak kırıklı ve çatlaklı yapı sunarlar ve bazı kesitlerde dalgalı sönme gösterirler.

Klinopiroksen (\% 13-25) yarı özşekilli iri fenokristaller halinde gözlenirler ve bol olarak opak mineral inklüzyonları içerirler (Şekil $5 \mathrm{c}, \mathrm{d}$ ). Genelde kırıklı ve çatlaklı yapı sunan iri klinopiroksenlerde, kenarlarından itibaren yenme ve kemirilme gözlenmektedir. Bazıları kısmen kloritleşmişlerdir.
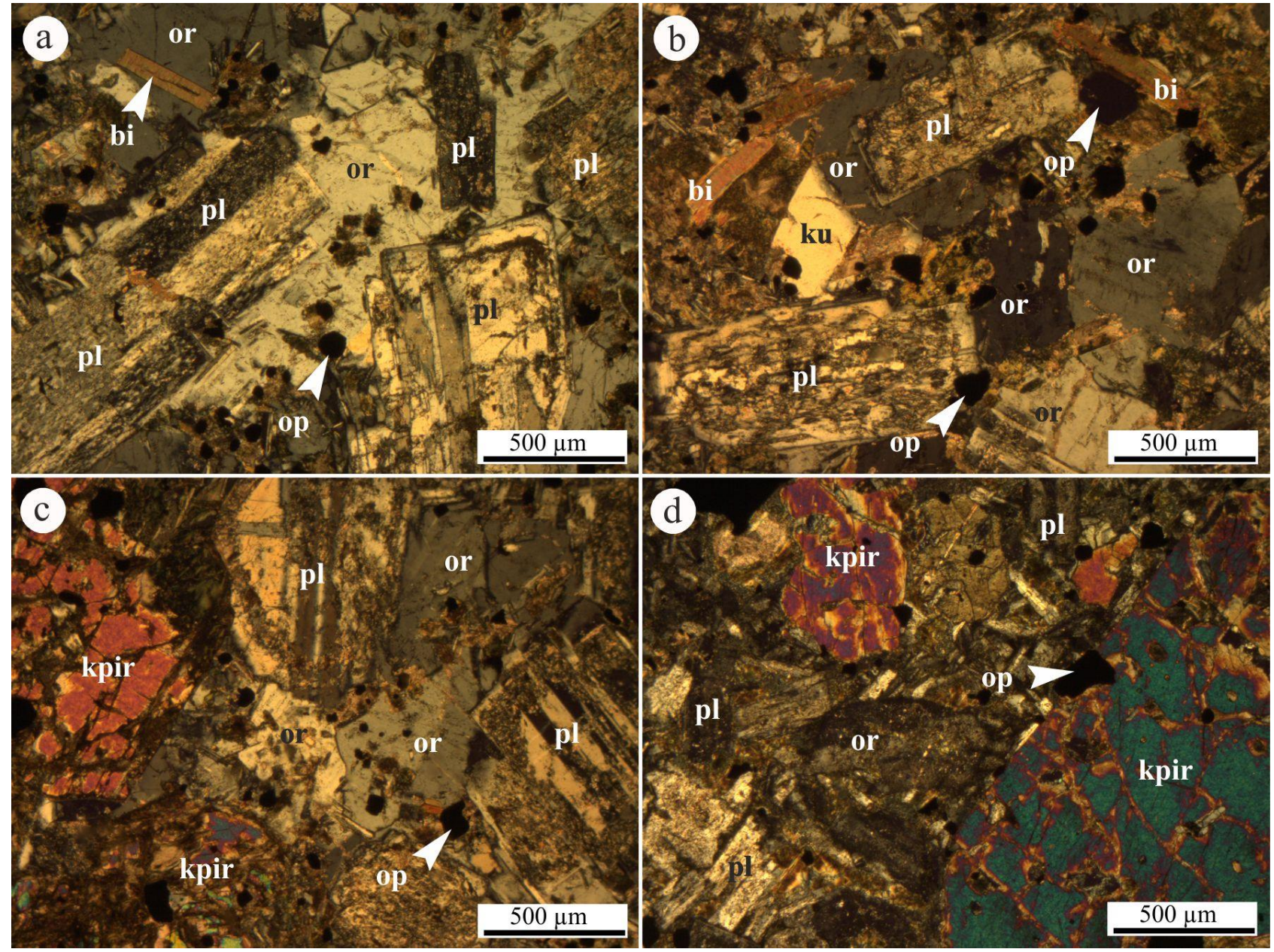

Şekil 5. Bozat Plütonu monzogabroyik kayaçlarına ait mikrofotoğraflar; (a) ortoklasın plajiyoklası çevrelemesi ile oluşan monzonitik doku ve biyotit ve opak mineralleri poikilitik olarak içermesi, (b) özşekilli plajiyoklas ve özşeklisiz ortoklas mineralleri ile küçük lata şekilli biyotit mineralleri, (c) opak mineral kapanımları içeren yuvarlağımsı ortoklaslar ve kenarları korrode olmuş, bol çatlaklı ve kırıklı özşekilsiz klinopiroksen mineralleri, (d) yarı özşekilli iri klinopiroksen minerali (Örnek No: BT-1, BT-8; Ç.N.) (Açıklamalar; Ç.N., çapraz nikol; kpir, klinopiroksen; bi,biyotit; pl, plajiyoklas; ku, kuvars; or, ortoklas; op, opak mineral). 
Biyotit (\% 2-6) genellikle yarı̈̈sşekilli ve özşekilli ince uzun krtistaller halindedir ve (001) yüzeyine paralel dilinimi belirgindir (Şekil $5 \mathrm{a}, \mathrm{b}$ ). Nadiren küçük kısa latalar halinde gözlenirler. Opak mineraller (\% 2-4) yarı öz ve özşekilsiz irili ufaklı kristaller halindedir (Şekil 5a-d). Opak mineraller genellikle mafik minerallerin nadiren de açık renkli minerallerin çevresinde ve bazen de içerisinde kapanımlar halinde gözlenirler.

\subsection{Mineral Kimyast}

Kayaçlardaki plajiyoklaslar; labradorit ve bitovnit olup, labradoritlerin bileşimleri $\mathrm{An}_{53-69} \mathrm{Ab}_{28-43} \mathrm{Or}_{1-8}$ arasında, bitovnitlerin bileşimleri ise $\mathrm{An}_{73-88} \mathrm{Ab}_{11 \text { - }}$

(a)

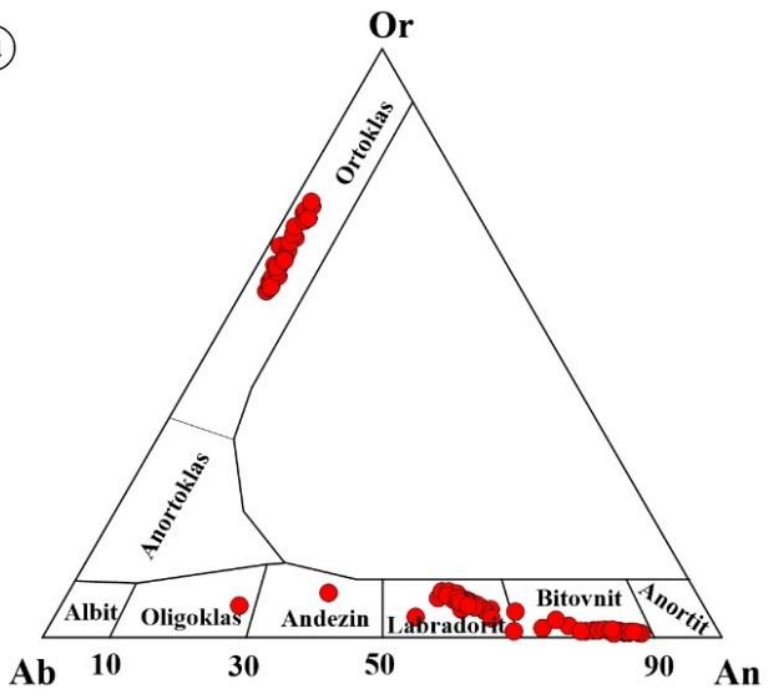

(c)

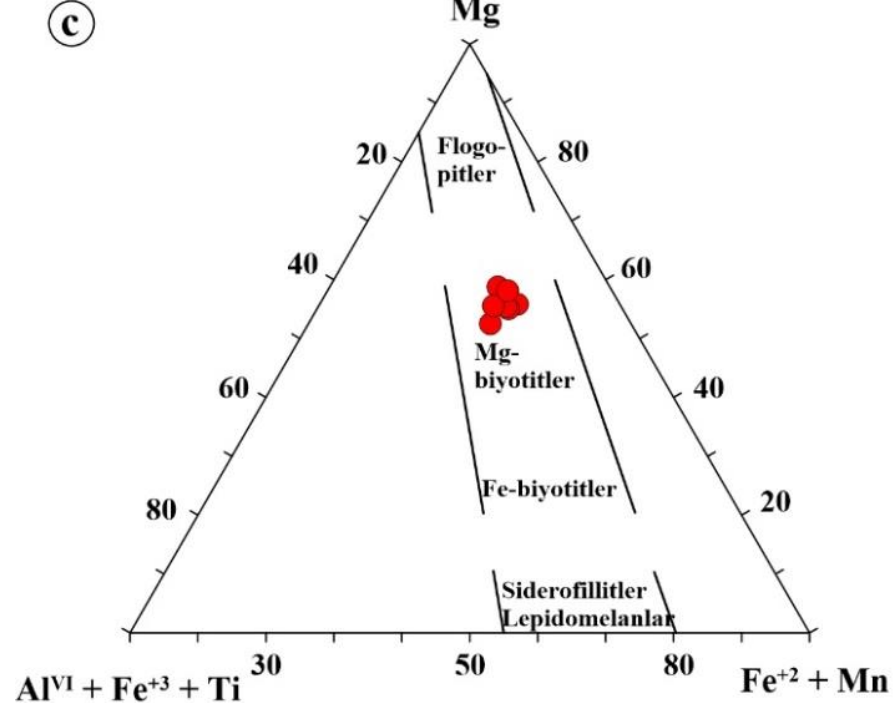

${ }_{26} \mathrm{Or}_{1-3}$ arasında değişmektedir. $\mathrm{Bu}$ kayaçlar içerisindeki K-feldispatlar; ortoklas olup, bileşimleri $\quad \mathrm{An}_{2-4} \mathrm{Ab}_{23-38} \mathrm{Or}_{59-74}$ arasında değişmektedir (Şekil 6a, Tablo 2). Klinopiroksenler; Morimoto vd. (1988)'nin yaptığı sınıflamaya göre diyopsitik ojit ve ojit olarak isimlendirilmiş olup, bileşimleri $\mathrm{Wo}_{40}$ ${ }_{45} \mathrm{En}_{42-44} \mathrm{Fs}_{12-17}$ arasinda, $\mathrm{Mg} /\left(\mathrm{Mg}+\mathrm{Fe}^{+2}\right)$ oran1 ise 0.70-0.78 arasında değișmektedir (Sekil 6b, Tablo 2). Biyotitler, $\mathrm{Mg}-\left(\mathrm{Al}^{\mathrm{VI}}+\mathrm{Fe}^{+3}+\mathrm{Ti}\right)-/\left(\mathrm{Fe}^{+2}+\mathrm{Mn}\right)$ üçgen diyagramında Mg-biyotitler alanına düşmekte olup, $\mathrm{Mg} /\left(\mathrm{Mg}+\mathrm{Fe}^{+2}\right)$ oranları $0.66-0.70$ arasında değişmektedir (Şekil 6c, Tablo 2). Fe-Ti oksitler; magnetit ve titano-magnetit olarak adlandırılmıştır (Şekil 6d, Tablo 2).

(b)

Monzogabro

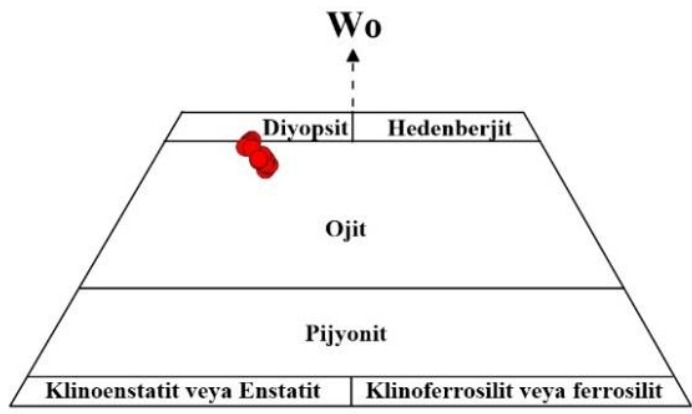

En

Fs

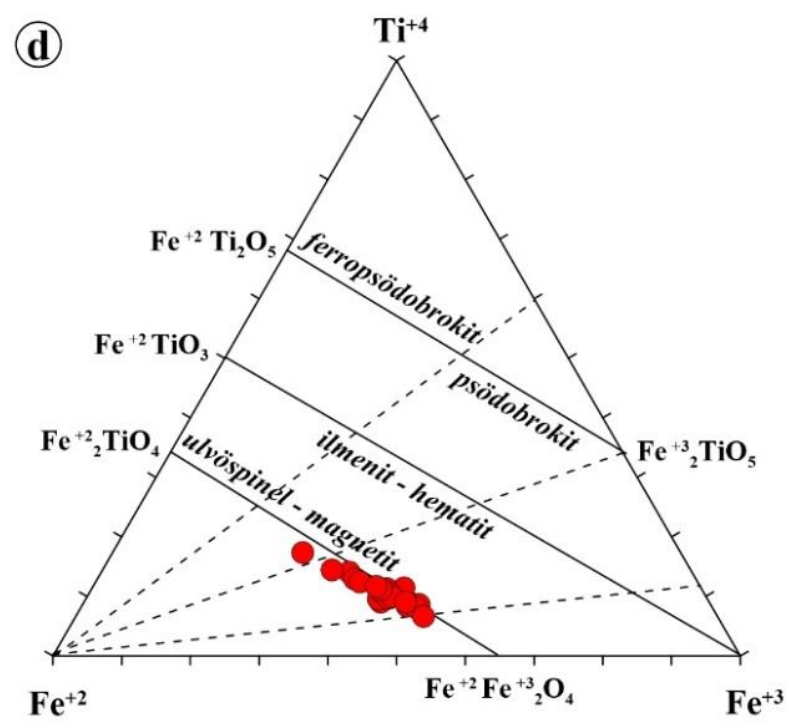

Şekil 6. Bozat Plütonu kayaçlarına ait; (a) feldispatların An-Ab-Or üçgen diyagramı (Deer vd., 1992), (b) klinopiroksenlerin Wo-En-Fs üçgen diyagramı (Morimoto vd., 1988), (c) biyotitlerin $\mathrm{Mg}-\left(\mathrm{Fe}^{+2}+\mathrm{Mn}\right)-\left(\mathrm{Al}^{\mathrm{VI}}\right.$ $+\mathrm{Fe}^{+3}+\mathrm{Ti}$ ) (apfu) diyagramı (Foster, 1960), (d) Fe-Ti oksitlerin $\mathrm{Ti}^{+4}-\mathrm{Fe}^{+2}-\mathrm{Fe}^{+3}$ (Bacon ve Hirschmann, 1988) diyagram1. 


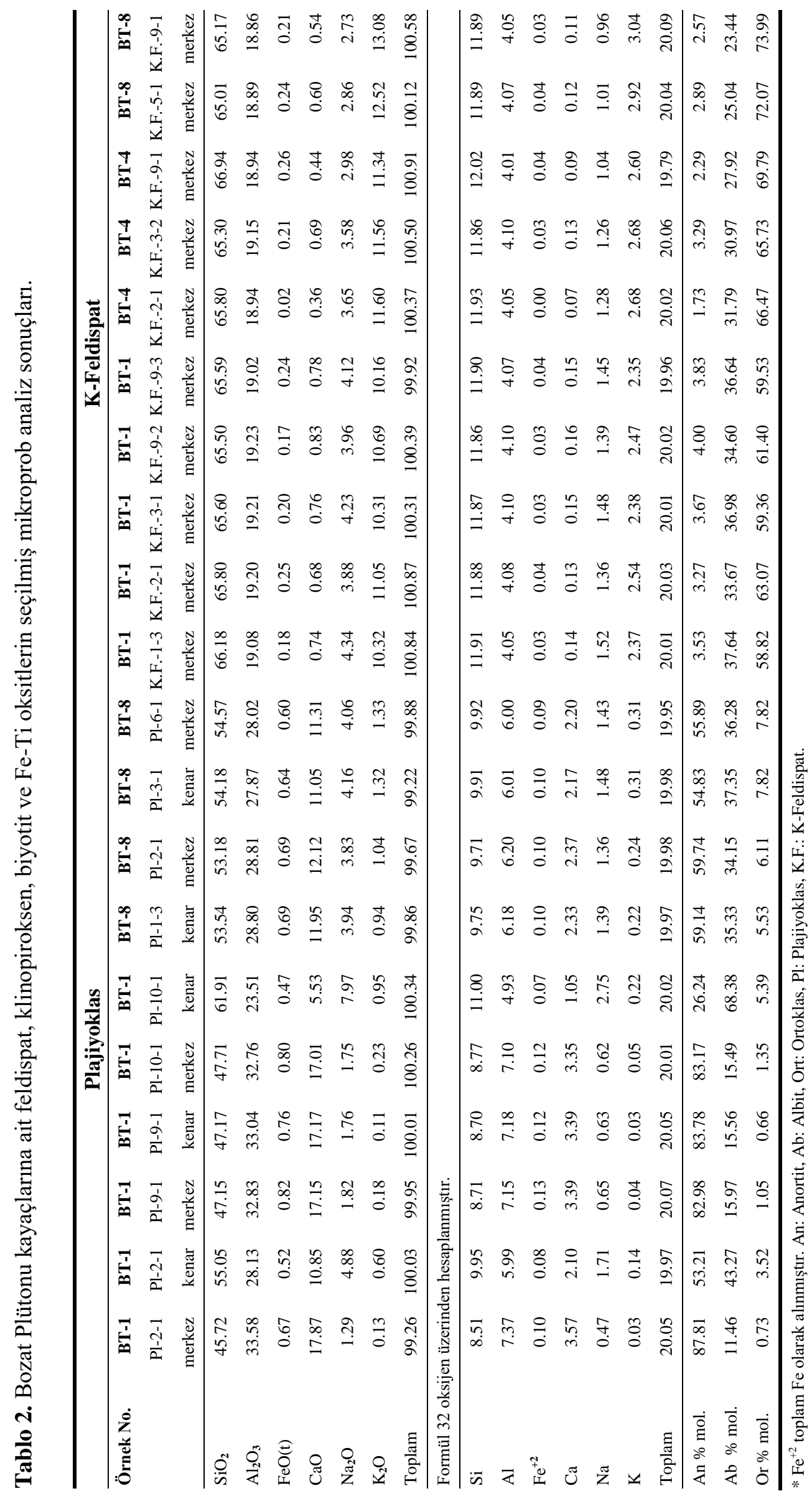




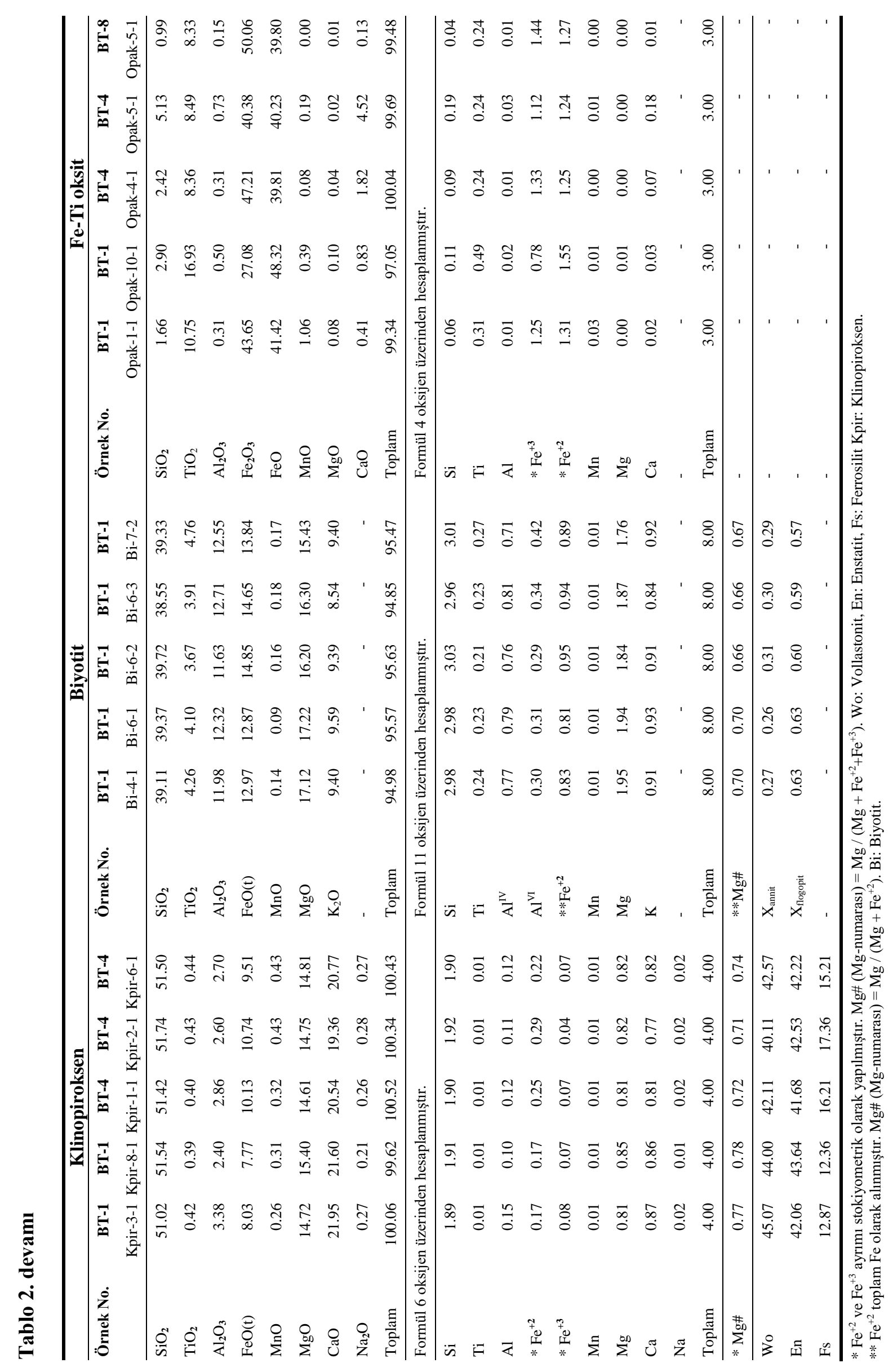




\subsection{Tüm-Kayaç Jeokimyası}

Bozat Plütonu'nu oluşturan kayaçların ana, iz ve nadir toprak element analizleri Tablo 3'de verilmiştir. Middlemost (1994)'un TAS (Toplam Alkali-Silis) sınıflama diyagramına göre plütona ait örneklerin monzodiyorit alanında yer aldığı görülmektedir (Şekil 7a). Ayrıca, yine bu diyagram üzerinde Miyashiro (1978)'nun alkalisubalkali ayırımına göre; plütona ait örnekler alkali karaktere sahiptir (Şekil 7a).

Plütona ait kayaçların, Le Maitre vd. (2002)'nin $\mathrm{SiO}_{2}(\%)$ karş1 $\mathrm{K}_{2} \mathrm{O}(\%)$ diyagramında (Şekil 7b) şoşonitik, Hastie vd. (2007)'nin Co (ppm) karş1 Th (ppm) diyagramında (Şekil 7c) ise yüksek-K ve şoşonitik karakterli olduğu görülmektedir. İncelenen pluton örnekleri, Maniar ve Piccoli (1989)'nin A/NK karşı A/CNK diyagramına (Şekil 7d) aktarıldığında, örneklerin I-tipi alanda yer aldığ1 ve metalümin karakterli olduğu belirlenmiştir.

İncelenen plütonu oluşturan kayaçların ilksel mantoya (Sun ve McDonough, 1989) normalize iz element dağılımları incelendiğinde; her iki plütonun genel olarak büyük iyon yarıçaplı litofil element (BILLE; $\mathrm{Sr}, \mathrm{K}_{2} \mathrm{O}, \mathrm{Rb}$ ve $\mathrm{Ba}$ ), Th ve $\mathrm{Ce}$ konsantrasyonları bakımından zenginleşme, bazı yüksek çekim alanlı element (YÇAE; Y ve $\mathrm{TiO}_{2}$ ), $\mathrm{Nb}$ ve Ta içerikleri bakımından fakirleşme göstermektedirler (Şekil 8a). Plütona ait kayaçların kondrite (Taylor ve McLennan, 1985) normalize nadir toprak element dağılımları $\left(\mathrm{La}_{N} / \mathrm{Lu}_{\mathrm{N}}=8.61-9.98, \quad \mathrm{La}_{N} / \mathrm{Yb}_{\mathrm{N}}=8.40-10.22\right), \quad \mathrm{Eu}$ anomalisinin $\left(\mathrm{Eu}_{\mathrm{N}} / \mathrm{Eu}^{*}=0.73-0.80\right)$ varlığ 1 ile karakterize edilen kaşık şekilli bir yönseme ile tanımlanır (Şekil 8b). Bu kayaçların gösterdiği hafif negatif $\mathrm{Eu}$ anomalisi, magmalarının gelişiminde feldispat ayrımlaşmasının az da olsa etkili olduğuna işaret etmektedir.

\section{Tartışma}

\subsection{Ana Magmaların Kökeni}

Genel olarak granitik-monzonitik magmaların kökenlerine ilişkin birçok petrojenetik model önerilmektedir. Bu magmalar; (1) manto kökenli bazaltik ana magmalardan fraksiyonel kristallenmesi (FC) ve/veya assimilasyon + fraksiyonel kristallenmesi (AFC) ile türeyebilir (Li vd., 2009; Aghazadeh vd., 2010, 2011), (2) mafik-ortaç meta-magmatik kabuk kayaçlarının kısmi ergimesiyle türeyebilir (Roberts ve Clemens, 1993; Köksal vd., 2013), (3) manto kökenli mafik magma ile kabuk kökenli felsik
Tablo 3. Bozat Plütonu kayaçlarının ana (\%), iz (ppm), nadir toprak element (ppm) analizleri.

\begin{tabular}{|c|c|c|c|c|c|}
\hline \multicolumn{6}{|c|}{ Bozat Plütonu (Monzogabro) } \\
\hline Örnek No: & $\begin{array}{l}\text { Saptama } \\
\text { Limitleri }\end{array}$ & BT-1 & BT-4 & BT-8 & BT-11 \\
\hline $\mathrm{SiO}_{2}$ & 0.01 & 51.46 & 51.61 & 52.9 & 51.86 \\
\hline $\mathrm{TiO}_{2}$ & 0.01 & 0.61 & 0.7 & 0.64 & 0.64 \\
\hline $\mathrm{Al}_{2} \mathrm{O}_{3}$ & 0.01 & 19.41 & 16.71 & 16.3 & 15.04 \\
\hline $\mathrm{Fe}_{2} \mathrm{O}_{3}(\mathrm{t})$ & 0.04 & 6.61 & 8.53 & 7.65 & 8.26 \\
\hline $\mathrm{MnO}$ & 0.01 & 0.16 & 0.14 & 0.13 & 0.15 \\
\hline $\mathrm{MgO}$ & 0.01 & 2.7 & 4.47 & 3.44 & 5.52 \\
\hline $\mathrm{CaO}$ & 0.01 & 7.48 & 5.72 & 6.99 & 7.17 \\
\hline $\mathrm{Na}_{2} \mathrm{O}$ & 0.01 & 3.02 & 3.23 & 2.12 & 3.14 \\
\hline $\mathrm{K}_{2} \mathrm{O}$ & 0.01 & 3.91 & 4.47 & 4.43 & 4.19 \\
\hline $\mathrm{P}_{2} \mathrm{O}_{5}$ & 0.01 & 0.37 & 0.32 & 0.31 & 0.27 \\
\hline A.K. & - & 4 & 3.8 & 4.8 & 3.4 \\
\hline Toplam & - & 99.73 & 99.7 & 99.7 & 99.64 \\
\hline $\mathrm{Zr}$ & 0.1 & 104.9 & 124.8 & 140 & 113.1 \\
\hline $\mathrm{Y}$ & 0.1 & 19.6 & 19.4 & 19.4 & 21 \\
\hline $\mathrm{Sr}$ & 0.5 & 593.4 & 486.6 & 504 & 573.5 \\
\hline $\mathrm{Rb}$ & 0.1 & 126.6 & 150.5 & 137 & 137.1 \\
\hline Th & 0.2 & 9 & 13.5 & 14.9 & 9.7 \\
\hline $\mathrm{Ta}$ & 0.1 & 0.4 & 0.5 & 0.4 & 0.4 \\
\hline $\mathrm{Sc}$ & 1.0 & 13 & 21 & 19 & 25 \\
\hline V & 8.0 & 169 & 245 & 207 & 223 \\
\hline $\mathrm{Pb}$ & 0.1 & 5 & 4.2 & 8.4 & 15.3 \\
\hline $\mathrm{Ni}$ & 0.1 & 4.7 & 11.9 & 12 & 17.7 \\
\hline $\mathrm{Co}$ & 0.1 & 16.2 & 24.7 & 20.5 & 28.2 \\
\hline $\mathrm{Cr}$ & 20 & 20 & 30 & 30 & 120 \\
\hline $\mathrm{Cs}$ & 0.1 & 1.2 & 1.8 & 4.6 & 0.6 \\
\hline $\mathrm{Ba}$ & 1.0 & 820 & 836 & 766 & 779 \\
\hline $\mathrm{Nb}$ & 0.1 & 7.1 & 6.9 & 7.6 & 5.9 \\
\hline $\mathrm{Hf}$ & 0.1 & 2.6 & 3.1 & 3.5 & 2.9 \\
\hline $\mathrm{La}$ & 0.1 & 28.3 & 28.2 & 29.8 & 27.1 \\
\hline $\mathrm{Ce}$ & 0.1 & 47.4 & 51.5 & 54.3 & 48.4 \\
\hline $\operatorname{Pr}$ & 0.02 & 5.89 & 6.03 & 6.34 & 5.79 \\
\hline $\mathrm{Nd}$ & 0.3 & 21.4 & 24.1 & 24.2 & 21.9 \\
\hline $\mathrm{Sm}$ & 0.05 & 4.61 & 4.74 & 4.74 & 4.56 \\
\hline $\mathrm{Eu}$ & 0.02 & 1.13 & 1.06 & 1.1 & 1.15 \\
\hline $\mathrm{Gd}$ & 0.05 & 4.09 & 4.14 & 4.23 & 4.28 \\
\hline $\mathrm{Tb}$ & 0.01 & 0.61 & 0.62 & 0.61 & 0.67 \\
\hline Dy & 0.05 & 3.28 & 3.39 & 3.49 & 3.88 \\
\hline Ho & 0.02 & 0.71 & 0.69 & 0.74 & 0.78 \\
\hline $\mathrm{Er}$ & 0.03 & 2.01 & 2.04 & 1.98 & 2.19 \\
\hline $\mathrm{Tm}$ & 0.01 & 0.3 & 0.3 & 0.31 & 0.32 \\
\hline $\mathrm{Yb}$ & 0.05 & 1.99 & 2.01 & 1.97 & 2.18 \\
\hline $\mathrm{Lu}$ & 0.01 & 0.3 & 0.34 & 0.31 & 0.32 \\
\hline $\mathrm{Eu}_{N} / \mathrm{Eu}^{*}$ & - & 0.80 & 0.73 & 0.75 & 0.80 \\
\hline $\mathrm{La}_{N} / \mathrm{Lu}_{\mathrm{N}}$ & - & 9.79 & 8.61 & 9.98 & 8.79 \\
\hline $\mathrm{La}_{\mathrm{N}} / \mathrm{Yb}_{\mathrm{N}}$ & - & 9.61 & 9.48 & 10.22 & 8.40 \\
\hline Mg\# & - & 26.05 & 31.12 & 27.94 & 36.56 \\
\hline
\end{tabular}

$\mathrm{Fe}_{2} \mathrm{O}_{3}(\mathrm{t}), \mathrm{Fe}_{2} \mathrm{O}_{3}$ cinsinden toplam demir. $\mathrm{Eu} *=\sqrt{ }\left(\mathrm{Sm}_{\mathrm{N}} * \mathrm{Gd}_{\mathrm{N}}\right)$.

$\mathrm{Mg} \#=100 *$ molar $\mathrm{MgO} /(\mathrm{MgO}+\mathrm{FeO})$.

A.K. (Ateşte Kayıp): Toplam uçucu içeriği. 

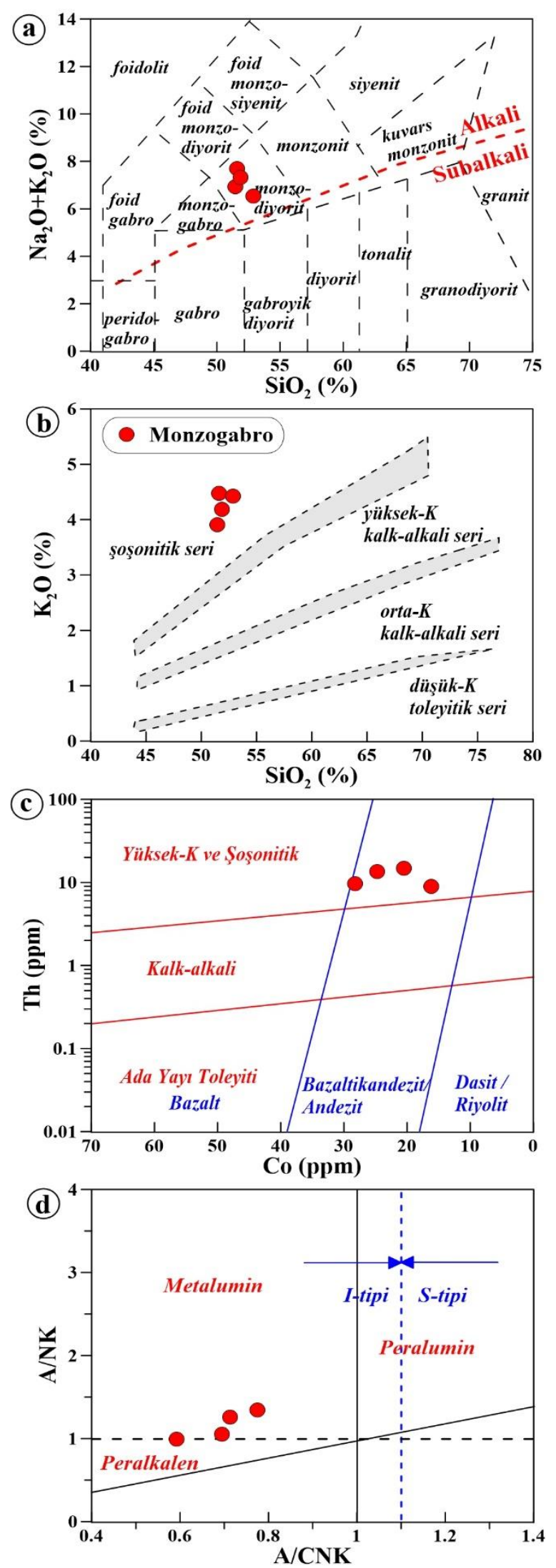

Şekil 7. Bozat Plütonu kayaçlarına ait; (a) $\mathrm{Na}_{2} \mathrm{O}+\mathrm{K}_{2} \mathrm{O}$ (\%) karşı $\mathrm{SiO}_{2} \quad$ (\%) (TAS) sinıflama diyagramı (Middlemost, 1994) (Alkali-subalkali ayırım çizgisi, Miyashiro (1978)'e göredir), (b) $\mathrm{SiO}_{2}$ (\%) karşı $\mathrm{K}_{2} \mathrm{O}$ (\%) diyagramı (Le Maitre vd., 2002), (c) Th (ppm) karşı Co (ppm) diyagramı (Hastie vd., 2007), (d) molar A/NK karşı molar (A/CNK) diyagramı (Maniar ve Piccoli, 1989).
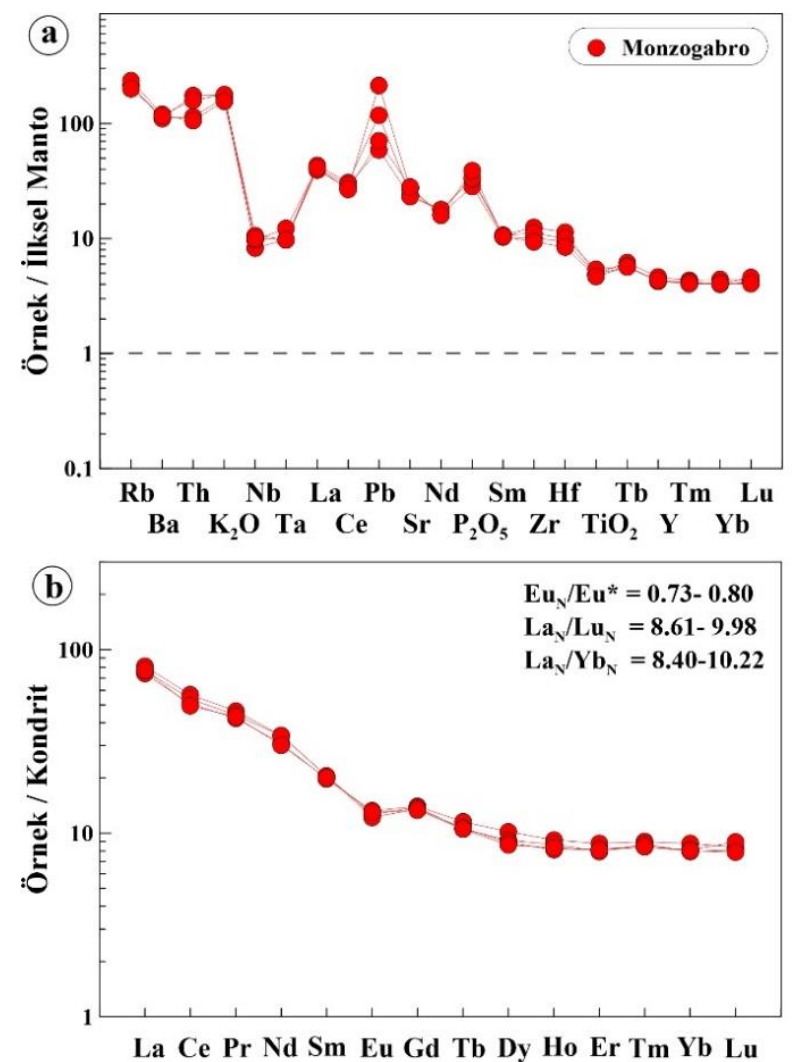

Şekil 8. Bozat Plütonu kayaçlarına ait; (a) ilksel mantoya (Sun ve McDonough, 1989) normalize edilmiş iz element dağılımları, (b) kondrite (Taylor ve McLennan, 1985) normalize edilmiş nadir toprak element dağılımları.

magmaların karışımıyla türeyebilir (Ackerman vd., 2010; Liu vd., 2014), (4) manto kökenli bazaltik magmaların kabuk kayaçlarını ergitmesi için 1sı sağlaması esas alınmakta olup (Roberts ve Clemens, 1993; Guffanti vd., 1996), yay magmaları mafik-ortaç bileşimli meta-magmatik (Rapp ve Watson, 1995; Singh ve Johannes, 1996) ya da meta-sedimanter (Patiño Douce ve Beard, 1996; Stevens vd., 1997) kayaçların kısmı ergimesinden türeyebilmektedir.

İncelenen Bozat Plütonu'nu oluşturan monzogabroyik kayaçlar $\left(\mathrm{SiO}_{2}: \%\right.$ 51.5-52.9 ve Mg\#: 26-37); I-tipi, metalümin ( $\mathrm{A} / \mathrm{CNK}=0.59$ 0.77 ) ve şoşonitik karakterli olup, çoğunlukla dar bir aralıkta değişen $\mathrm{Nb} / \mathrm{Y}$ oranlarıyla nispeten yitim zeginleşmesi yönsemesi göstermektedirler (Şekil 9a). Ayrıca, plütona ait kayaçlar, Eby (1992)'nin $\mathrm{Nb}-\mathrm{Y}-\mathrm{Ga} * 3$ diyagramına göre mantokabuk etkileşimi sonucu magmatik veya kabuk kökenli alanında yer aldıkları görülmektedir (Şekil 9b). 
(a)

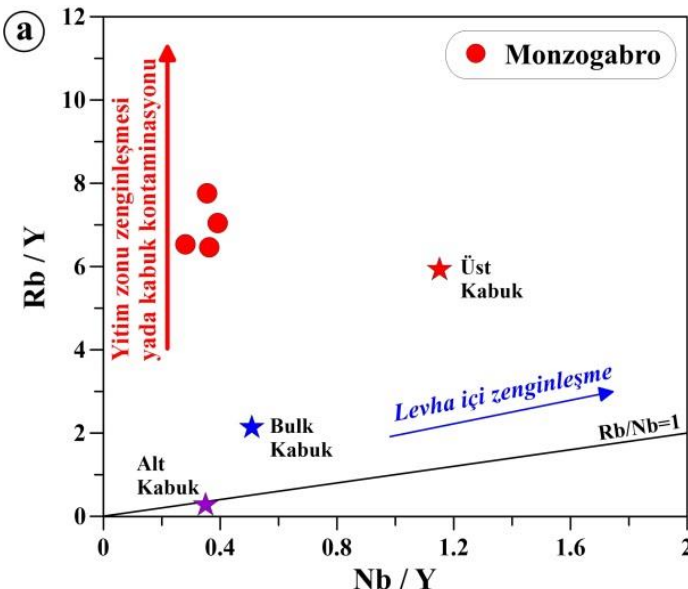

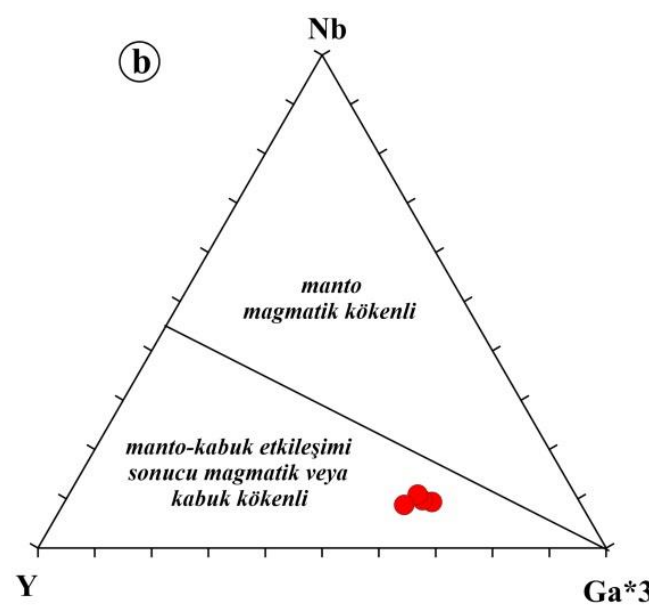

Şekil 9. Bozat Plütonu kayaçlarına ait (a) Nb/Y - Rb/Y ve (b) Nb-Y-Ga*3 (Eby, 1992) diyagramları.

İncelenen plüton kayaçlarının ilksel mantoya normalize iz element diyagramlarındaki negatif $\mathrm{Nb}$, Ta ve $\mathrm{TiO}_{2}$ anomalileri ve $\mathrm{Sr}, \mathrm{Rb}, \mathrm{K}_{2} \mathrm{O}$, Th, Ce ve La zenginleşmeleri ile yüksek BİLE/YÇAE oranları, plütonu oluşturan kayaçların (a) ana magmanın(ların) yitimle ilişkili farklı derecedeki akışkan \pm ergiyik zenginleşmesi, (b) ana magmanın(ların) kabuk magma odalarındaki farklı ayrımlaşma \pm asimilasyon yolları ile açıklanabilir. Bunlara ilave olarak, plütonun kondrite normalize NTE dağılımlarında hafif-orta derecede zenginleşmeye $\left(\mathrm{La}_{\mathrm{N}} / \mathrm{Lu}_{\mathrm{N}}:\right.$ 8.61-9.98, $\quad \mathrm{La}_{\mathrm{N}} / \mathrm{Yb}_{\mathrm{N}}$ : 8.40-10.22) sahip olmas1, Bozat Plütonu'nun ana magmasının alt kıtasal kabuk ve zenginleşmiş litosferik manto ergiyiklerinden türediğini ve kıtasal magma odasında farklılaşarak yerleştiğine işaret etmektedir.

\subsection{Fraksiyonel Kristallenme (FC) ve Asimilasyon-Fraksiyonel Kristallenme (AFC)}

İncelenen plütonu oluşturan kayaçların bazı iz element değişimlerinde gözlenen korelasyonlar (Şekil 10a-d), bu kayaçların gelişiminde plajiyoklas + K-feldispat + klinopiroksen \pm biyotit fraksiyonlaşmasının etkili olduğuna işaret etmektedir.

\begin{abstract}
Şekil 10. Bozat
Plütonu kayaçlarına

ait mineral

fraksiyonlaşma

yönlerini gösterir; (a)

$\mathrm{Rb}$ (ppm) karşı

$\mathrm{K}_{2} \mathrm{O} / \mathrm{Rb}$, (b) $\mathrm{Sr}$ (ppm) karşı $\mathrm{Ba}(\mathrm{ppm}),(\mathbf{c}) \mathrm{Sr}$ (ppm) karş1 $\mathrm{Eu}_{\mathrm{N}} / \mathrm{Eu}^{*}$ ve (d) $\mathrm{Sr}$ (ppm) karş1 $\mathrm{Rb}(\mathrm{pm})$ diyagramları (plj: plajiyoklas, kpir: klinopiroksen, hbl: hornblend, bi: biyotit, K-feld: K-feldispat).
\end{abstract}
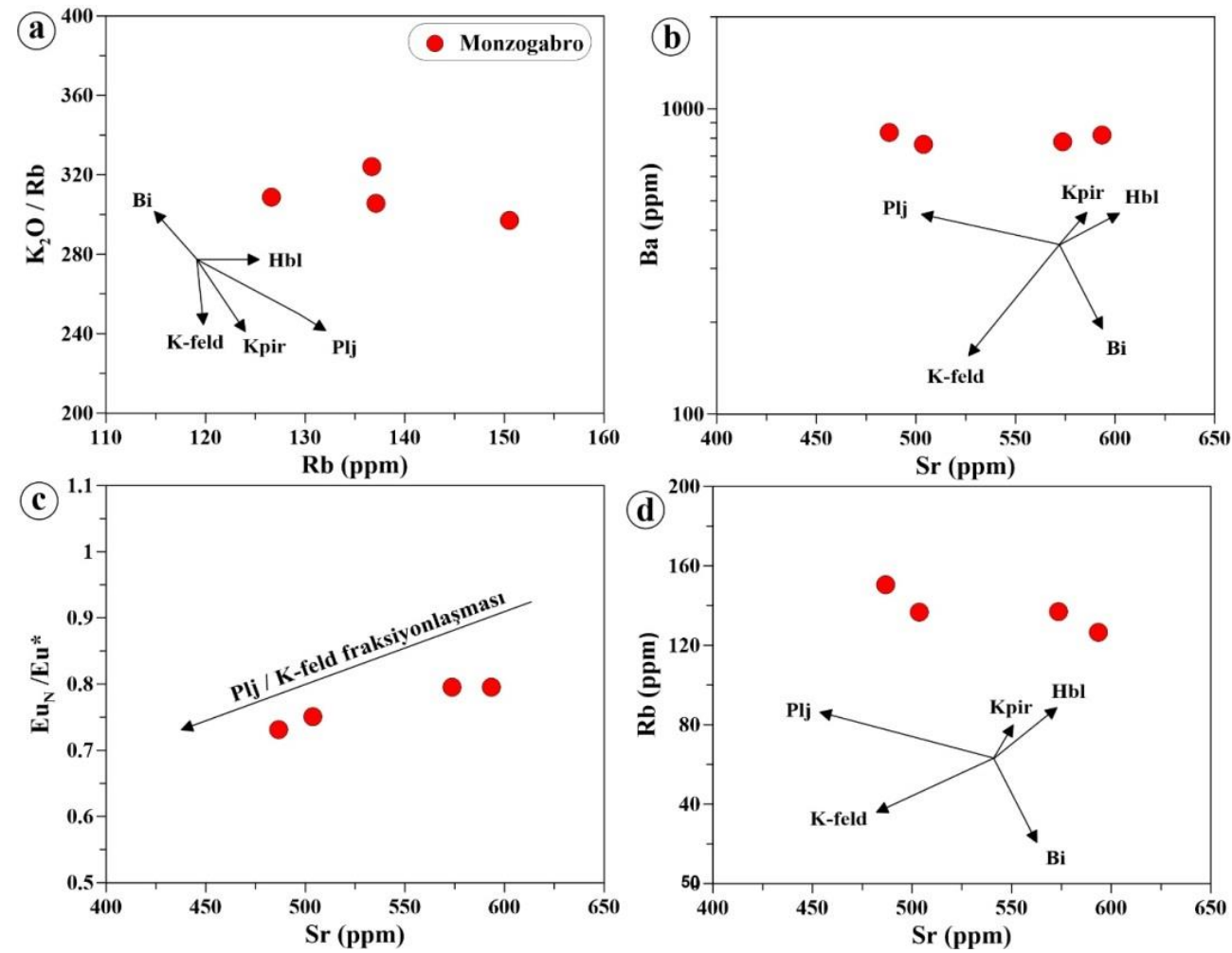
İncelenen pluton kayaçlarının NTE dağılımlarında konkav şekilli bir desen sunması gelişimlerinde klinopiroksen fraksiyonlaşmasının (Thirlwall vd., 1994) etkili olduğunu doğrulamaktadır. Ayrıca, kayaçlarda gözlenen hafif negatif $\mathrm{Eu}$ anomalisi $\left(\mathrm{Eu}_{\mathrm{N}} / \mathrm{Eu}^{*}\right.$ : 0.73-0.80), plutonun gelişiminde muhtemelen K-feldispat \pm plajiyoklas fraksiyonlaşmasının etkili olduğunu ifade etmektedir. Bazı iz element değişimlerinde gözlenen düzensiz korelasyonlar ile petrografik olarak gözlenen dengesizlik dokuları, incelenen plütonun gelişiminde etkili olan fraksiyonel kristalleşmenin yanı sıra kabuk asimilasyonu \pm magma karışımı olaylarına da işaret edebilmektedir. İncelenen plütonun gelişiminde kıtasal kabuk asimilasyonunun (AFC) varlığ $\mathrm{Ta} / \mathrm{Yb}$ karşı $\mathrm{Th} / \mathrm{Yb}$ diyagramıyla da (Şekil 11) açıklanabilir (Pearce, 1983). Bu diyagramda, incelenen plütonik kayaç örnekleri, yüksek $\mathrm{Th} / \mathrm{Yb}$ ve $\mathrm{Ta} / \mathrm{Yb}$ oranları ile ortalama kitasal kabuk değerine doğru bir yönseme göstermektedir (Şekil 11). Buna göre, incelenen plütonun ana magmasının yitim bileşenlerince zenginleşmiş bir kaynaktan itibaren türediği ve daha sonra da AFC ile geliştiği söylenebilir (Şekil 11).

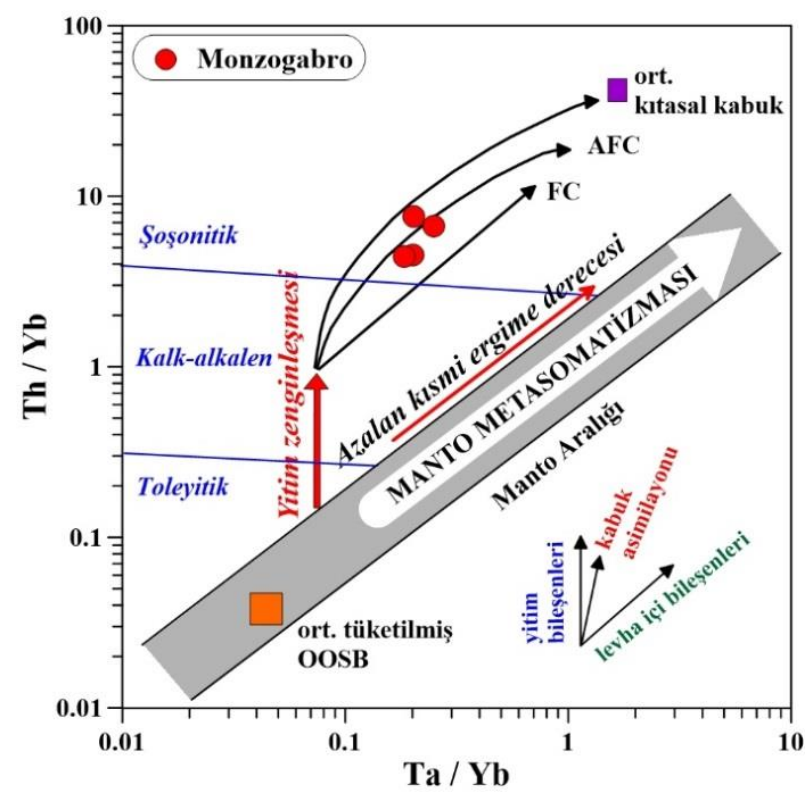

Şekil 11. Bozat Plütonu kayaçlarına ait fraksiyonel kristallenme (FC) ve/veya asimilasyon-fraksiyonel kristallenme (AFC) yönlerini gösterir $\mathrm{Ta} / \mathrm{Yb}$ 'a karşı $\mathrm{Th} / \mathrm{Yb}$ (Pearce, 1983) diyagramı. FC (fraksiyonel kristallenme), AFC (asimilasyon+fraksiyonel kristallenme), yitim zenginleşmesi ve manto metazomatizmasını gösterir vektörler Pearce vd. (1990)'den alınmıştır.

\subsection{Plütonların Oluştuğu Magma-Tektonik Ortam}

DPOK'de yitimin yönü, yitimin sonlanma zamanı, Torid-Anatolid Platformu ve Avrasya levhasinın çarpışma zamanı ile ilgili görüş farklılıklarından dolayı farklı jeodinamik modeller öngörülmüştür. $\mathrm{Bu}$ nedenle, Doğu Pontidlerin yitim polaritesi ve jeodinamik gelişimi hala tartışmalı olup, tartışmalar başlıca üç gurup altında toplanmaktadır: (1) Paleozoyik'ten Eosen sonlarına kadar süregelen kuzeye doğru olan bir yitim (Gedikoğlu, 1983; Ustaömer ve Robertson, 1995; Okay ve Tüysüz, 1999; Ustaömer ve Robertson, 2010; Ustaömer vd., 2013; Topuz vd., 2013; Okay vd., 2013), (2) Paleotetis'in Pontidler'in kuzeyinde olduğu ve Paleozoyik sonundan Eosen sonuna kadar devam eden güney yönlü bir yitim (Dewey vd., 1973; Bektaş vd., 1984, 1999; Chorowicz vd., 1998; Eyüboğlu vd., 2011), (3) Dogger'e kadar güneye, Üst Kretase'den Eosen sonuna kadar ise kuzeye doğru olan çift yönlü bir yitim (Şengör ve Y1lmaz, 1981) modelleri ileri sürülmüştür.

Doğu Pontidlerin, Mesozoyik döneminde Neotetis okyanusu kuzey kolunun Avrasya levhası altına doğru yitimiyle gelişen kıtasal yay olduğu kabul edilmektedir (Okay ve Şahintürk, 1997; Şengör ve Y1lmaz, 1981; Y1lmaz vd., 1997). Neotetis okyanusunun güney kenarı Torid-Anatolid platformu (TAP) pasif olduğundan, kuzey yönlü Üst Kretase yitim modelinde (Şengör ve Y1lmaz, 1981; Okay ve Tüysüz, 1999; Şengör vd., 2003; Altherr vd., 2008), yiten kabuk zaman içerisinde soğur ve yaşlanır. Ayrıca, Üst Kretase döneminde Pontid kitasal yayının, yay gerisi havzada (Karadeniz'in açılması) gelişen gerilme sebebiyle de hızlı bir şekilde inceldiği ileri sürülmektedir (Robinson vd., 1995; Okay ve Şahintürk, 1997). $\mathrm{Bu}$ nedenle, Pontidler'deki Mesozoyik magmatizmasının ürünleri, yitimle ilişkili gerilmeli yay ortamında oluşan kalk-alkaliden yüksek-K'lu kalk-alkaliye kadar değişen karaktere sahip volkanik kayaçlarla temsil edilmektedir (ör., Okay ve Şahintürk, 1997; Y1lmaz ve Boztuğ, 1996; Okay ve Tüysüz, 1999; Altherr vd., 2008; Sipahi vd., 2014; Sipahi ve Sadıklar, 2014; Aydınçakır, 2016; Gülmez vd., 2016; Sipahi, 2017). Ayrica, bölgede Üst Kretase döneminde gelişmiş yitimle ilişkili I-tipi, kalk-alkali, yüksek K'lu-şoşonitik karakterli plütonik kayaçların ( 90-65 My) da yaygın olduğu iyi bilinmektedir (ör., Dokuz vd., 2006; Karsl1 vd., 2010; Kaygusuz ve Aydınçakır, 2009, 2011; Kaygusuz vd., 2008, 2009, 2013, 2014). 
İncelenen Bozat Plütonu'nun magma-tektonik ortamını belirlemek için plütonik kayaçlar için geliştirilen ayırtman diyagramlar kullanılmıştır. Pearce vd. (1984)'nin Rb-(Y+Nb) diyagramına (Şekil 12a) göre incelenen plütona ait örnekler, volkanik yay granitleri (VAG) alanına düşmektedirler. Ayrıca, plütona ait kayaçlar Thiéblemont ve Tégyey (1994)'in Zr (ppm) karş1 $\mathrm{Nb}_{\mathrm{N}} / \mathrm{Zr}_{\mathrm{N}}$ diyagramında yitimle ilişkili granitoyidler alanında, Harris vd. (1986)'nin $\mathrm{Rb} / 30-\mathrm{Hf}-\mathrm{Ta} * 3$ (Şekil 12b) üçgen diyagramına göre de yay granitleri alanında yeraldıkları görülmektedir (Şekil 12c). Ayrıca, Doğu Pontidler kıtasal yayının, Üst Kretase (Senoniyen) döneminde denizaltı ortamında gelişen yoğun bimodal volkanizma ürünlerinin (mafik-felsik) olması nedeniyle gerilmeli bir yay olduğu bilinmektedir (ör., Bektaş vd., 1995; Arslan vd., 1997; Okay ve Şahintürk, 1997). Dolayısıyla, diğer jeolojik ve jeokimyasal veriler de dikkate alındığında, Geç Kretase yaşlı I-tipi, metalümin, şoşonitik karakterli Bozat Plütonu'nun tektonomagmatik gelişimi, kıtasal yay ortamında yitim akışkanları/sedimanları ile zenginleşmiş litosferik manto ve alt kabuktan türeyen ana magmanın gerilmeli yay ortamında yerleşmesiyle açıklanabilir.

\section{Sonuçlar}

Geç Kretase yaşlı Bozat Plütonu monzogabro bileşimli kayaçlardan oluşmaktadır. Petrografik olarak, incelenen plüton kayaçları ince-orta taneli ve genellikle monzonitik, poikilitik, nadiren pertitik dokulu olup, plajiyoklas, ortoklas, kuvars, klinopiroksen, biyotit, Fe-Ti oksit içermektedir. Ayrıca, bu plütonda dengesiz kristallenmeye işaret eden; klinopiroksenlerin kenarlarının kemirilmesi ve yenmesi, ortoklas minerallerinde gözlenen poikilitik doku gibi bazı dokusal özellikler gözlenmektedir.

Tüm-kaya jeokimya verileri incelenen plütonun Itipi, metalümin ve şoşonitik karaktere sahip olduğunu göstermektedir. Ayrıca, ana ve iz element değişimleri, plütonun kıtasal kabuktaki bir magma odasının gelişimi sırasında önemli derecede fraksiyonel kristallenme ve daha az oranda kabuk asimilasyonuyla geliştiklerini ortaya koymaktadır. Plütonu oluşturan ana magmanın gerilmeli bir yay ortamında, litosferik manto kökenli ergiyikler ile alt kabuk kökenli ergiyiklerin karışımından oluştuğu ileri sürülebilir.
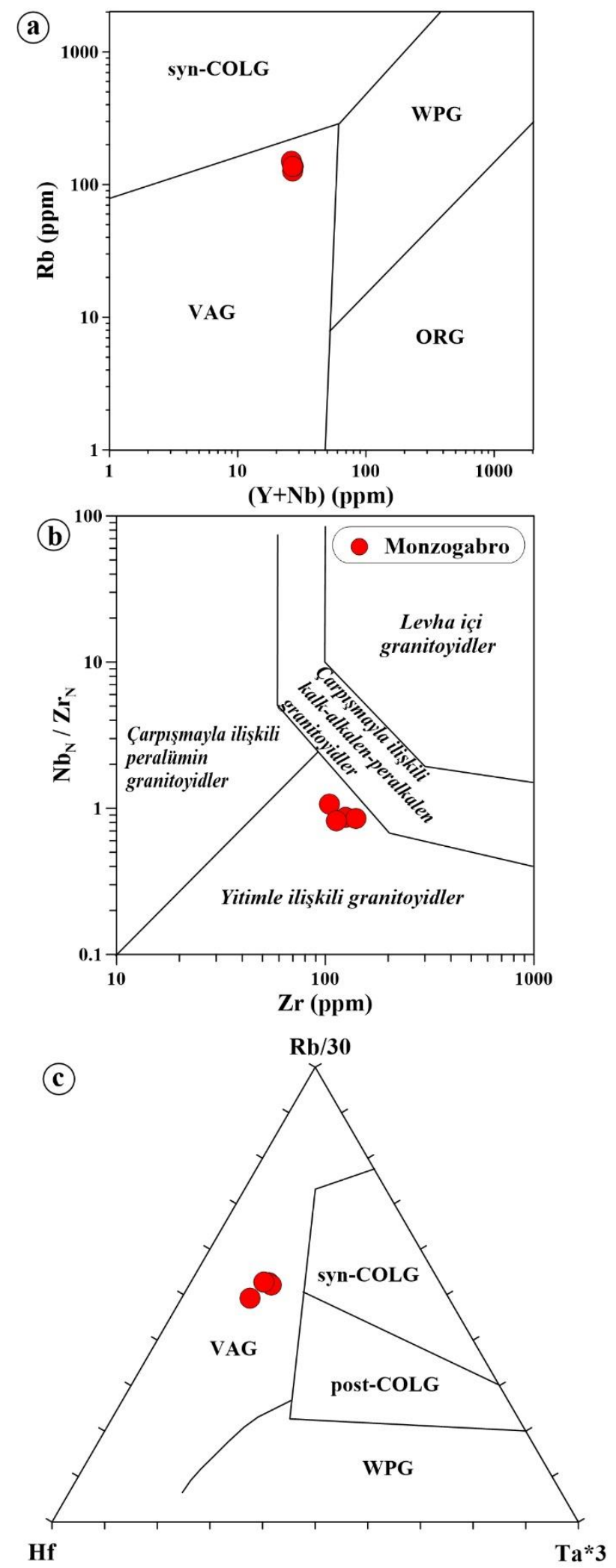

Şekil 12. Bozat Plütonu kayaçlarına ait magmatektonik ortam ayrım diyagramları; (a) $\mathrm{Rb}(\mathrm{ppm})$ karş1 (Y+Nb) (ppm) (Pearce vd., 1984), (b) $\mathrm{Nb}_{\mathrm{N}} / \mathrm{Zr}_{\mathrm{N}}$ karşı $\mathrm{Zr}$ (ppm) (Thiéblemont ve Tégyey, 1994) ve (c) Rb/30-Hf-Ta*3 (Harris vd., 1986) diyagramları. syn-COLG, çarpışma ile eş yaşlı granitler; VAG, volkanik yay granitleri; WPG, levha-içi granitleri; ORG, okyanus sırtı granitleri; post-COLG, çarpışma sonrası granitleri. 


\section{Katkı Belirtme}

Bu çalışma, FBA-2018-7747 No'lu Karadeniz Teknik Üniversitesi Bilimsel Araştırma Projeleri (KTÜ-BAP) ile desteklenmiştir. Yazarlar, makaleye yapıcı eleştiri ve görüşleriyle katkı sağlayan dergi editörleri ve hakemlere teşekkür eder.

\section{Kaynaklar}

Ackerman, L., Krňanská, M., Siebel, W. ve Strnad, L. 2010. Geochemistry of the Drahotín and Mutěnín intrusions, West Bohemian shear zone, Bohemian massif: contrasting evolution of mantle-derived melts. Mineralogy and Petrology, 99, 185-199.

Aghazadeh, M., Castro, A., Omran, N.R., Emami, M.H., Moinvaziri, H. Ve Badrzadeh, Z. 2010. The gabbro (shoshonitic)-monzonitegranodiorite association of Khankandi pluton, Alborz Mountains, NW Iran. Journal of Asian Earth Sciences, 38, 199-219.

Aghazadeh, M., Castro, A., Badrzadeh, Z. ve Vogt, K. 2011. Post-collisional polycyclic plutonism from the Zagros hinterland. The Shaivar-Dagh plutonic complex Alborz belt, Iran. Geological Magazine, 148, 980-1008.

Altherr, R., Topuz, G., Siebel,W., Şen, C., Meyer, H.P. ve Satır, M. 2008. Geochemical and Sr-Nd-Pb isotopic characteristics of Paleocene plagioleucitites from the Eastern Pontides (NE Turkey). Lithos, 105, 149-161.

Arslan, M. ve Aslan, Z. 2006. Mineralogy, petrography and whole-rock geochemistry of the Tertiary granitic intrusions in the eastern Pontides. Turkey. Journal of Asian Earth Sciences, 27, 177-193.

Arslan, M., Tüysüz, N., Korkmaz, S. ve Kurt, H. 1997. Geochemistry and Petrogenesis of the Eastern Pontide Volcanic Rocks, Northeast Turkey. Chemi der Erde, 57, 157-187.

Arslan, M., Temizel, İ., Abdioğlu, E., Kolaylı, H., Yücel, C., Boztuğ, D. ve Şen, C. 2013. ${ }^{40} \mathrm{Ar}-$

${ }^{39} \mathrm{Ar}$ dating, whole-rock and $\mathrm{Sr}-\mathrm{Nd}-\mathrm{Pb}$ isotope geochemistry of post-collisional Eocene volcanic rocks in the southern part of the Eastern Pontides (NE Turkey): Implications for magma evolution in extension-induced origin. Contribution to Mineralogy and Petrology, 166, 113-142.

Aslan, Z., Arslan M. ve Şen, C. 1999. Doğu Pontidlerin Kuzey ve Güney zonlarında yüzeylenen Eosen yaşlı granitik sokulumların karşılaştırmalı jeolojik, petrografik ve jeokimyasal özellikleri.
Türkiye Jeoloji Kurultayı Bildiriler Kitabı, 223230.

Aydınçakır, 2016. Subduction related Late Cretaceous high $\mathrm{K}$ volcanism in the Central Pontides orogenic belt Constraints on geodynamic implications. Geodinamica Acta, 28 (4), 379411.

Bacon, C. R. ve Hirschmann, M. M. 1988. Mg/Mn partitioning as a test for equilibrium between coexisting $\mathrm{Fe}-\mathrm{Ti}$ oxides. American Mineralogist, 73, 57-61.

Bektaş, O., Pelin, S. ve Korkmaz, S. 1984. Doğu Pontid yay gerisi havzasında manto yükselimi ve polijenetik ofiyolit olgusu. TJK Ketin Sempozyumu, 175-188.

Bektaş, O., Yılmaz, C., Taslı, K., Akdağ, K. ve Özgür, S. 1995. Cretaceous rifting of the Eastern Pontide carbonate platform, NE Turkey: The formation of carbonate breccias and turbitides as evidence of a drowned platform. Geologia, 57, 233-244.

Bektaş, O., Şen, C., Atıcı, Y. ve Köprübaşı, N. 1999. Migration of the Upper Cretaceous subductionrelated volcanism towards the back-arc basin of the Eastern Pontide magmatic arc (NE Turkey). Geological Journal, 34, 95-106.

Chorowicz, J., Collet, B., Bonavia, F., Mohr, P., Parrot, J.F. ve Tesfaye, K. 1998. The Tana basin, Ethiopia: Intra-plateau uplift, rifting and subsidence. Tectonophysics, 295, 351-367.

Deer, W.A., Howie, R.A. ve Zussman, J. 1992. An introduction to the Rock Forming Minerals (second edition), London, Longman, 696.

Dewey, J.F., Pitman, W., Ryan, W. ve Bonnin, I. 1973. Plate tectonics and the evolution of the Alpine system, Geological Society American Bulletin, 84, 3137-3180.

Dokuz, A. 2011. Slab Detachment and Delamination Model for the Generation of Carboniferous High-Potassium I-type Magmatism in the Eastern Pontides, NE Turkey: The Köse Composite Pluton. Gondwana Research, 19, 926-944.

Dokuz, A. ve Tanyolu, E. 2006. Geochemical constraints on the provenance, mineral sorting and subaerial weathering of lower Jurassic and upper Cretaceous clastic rocks from the Eastern Pontides, Yusufeli (Artvin), NE Turkey. Turkish Journal of Earth Sciences, 15, 181-209.

Dokuz, A., Karslı, O., Chen, B. ve Uysal, İ. 2010. Sources and petrogenesis of Jurassic granitoids in the Yusufeli area, Northeastern Turkey: Implications for pre- and postcollisional 
lithospheric thinning of the Eastern Pontides. Tectonophysics, 480, 259-279.

Dokuz, A., Aydincakir, E., Kandemir, R., Karsli O., Siebel, W., Derman, A.S., Turan, M., 2017. Late Jurassic Magmatism and Stratigraphy in the Eastern Sakarya Zone, Turkey: Evidence for the Slab Breakoff of Paleotethyan Oceanic Lithosphere. Journal of Geology, 125, 1-31.

Eby, G.N. 1992. Chemical subdivision of the A-type granitoids: petrogenetic and tectonic implications. Geology, 20, 641-644.

Eyüboğlu, Y., Chung, S.L., Dudas, F.O., Santosh, M. ve Akaryali, E. 2011. Transition from shoshonitic to adakitic magmatism in the eastern Pontides, NE Turkey: implications for slab window melting. Gondwana Research, 19, 413-429.

Foster, M.D., 1960. Interpretation of the composition of trioctahedral micas. US Geological Survey Professional Paper, 354-B, 11-49.

Gedikoğlu, A. 1983. Doğu Pontid'lerdeki metalik maden yataklarının plaka tektoniği ile olan ilişkileri, 37. T.J.K. Bilimsel ve Teknik Kurultayı, Bildiri Özetleri, 86-87. Ankara.

Guffanti, M., Clynne, M. A. ve Muffler, L.J.P. 1996. Thermal and Mass İmplications of Magmatic Evolution in the Lassen Volcanic Region, California, and Constraints on Basalt Influx to the Lower Crust. Journal of Geophysical Research, 101, 3001-3013.

Gülmez, F., Genç, Ş.C., Prelević, D., Tüysüz, O., Karacik, Z., Roden, M.F., Billor, Z., 2016. Ultrapotassic volcanism from the waning stage of the Neotethyan subduction: a key study from the Izmir-Ankara-Erzincan Suture Belt, Central Northern Turkey. Journal of Petrology, 57, 561593.

Güven, İ.H. 1993. Doğu Pontidler'in 1/250000 Ölçekli Kompilasyonu, Maden Tetkik ve Arama Genel Müdürlüğü, Ankara.

Harris, N.B.W., Pearce, J.A. ve Tindle, A.G. 1986. Geochemical characteristics of collision- zone magmatism. In: Coward M.P, Ries A.C. (eds.), Collision Tectonics. Geological Society of London Special Publication, 19, 67-81.

Hastie, A.R., Kerr, A.C., Pearce, J.A. ve Mitchell, S.F. 2007. Classification of Altered Volcanic Island Arc Rocks using Immobile Trace Elements: Development of the Th-Co Discrimination Diagram. Journal of Petrology, 48, 12, 23412357.

Karslı, O., Chen, B., Aydin, F. ve Şen, C. 2007. Geochemical and $\mathrm{Sr}-\mathrm{Nd}-\mathrm{Pb}$ isotopic compositions of the Eocene Dölek and Sarıçiçek Plutons, Eastern Turkey: implications for magma interaction in the genesis of high-K calc-alkaline granitoids in a post-collision extensional setting. Lithos, 98, 67-96.

Karsl1, O., Dokuz, A., Uysal, İ., Aydin, F., Bin, C., Kandemir, R.ve Wijbrans, R.J. 2010. Relative contributions of crust and mantle to generation of Campanian high-K calc-alkaline I-type granitoids in a subdution setting, with special reference to the Harşit pluton, Eastern Turkey. Contributions to Mineralogy and Petrology, 160, 467-487.

Karsl1, O., Uysal, İ., Ketenci, M., Dokuz, A., Kandemir, R. ve Wijbrans, J. 2011. Adakite-like granitoid porphyries in the Eastern Turkey: potential parental melts and geodynamic implications. Lithos, 127, 354-372.

Karslı, O., Caran, Ş., Dokuz, A., Çoban, H., Chen, B. ve Kandemir, R. 2012a. A-type granitoids from the Eastern Pontides, NE Turkey: Records for generation of hybrid A-type rocks in a subduction-related environment. Tectonophysics, 530-531, 208-224.

Karsl1, O., Dokuz, A., Uysal, İ., Ketenci, M., Chen, B. ve Kandemir, R. 2012b. Deciphering the shoshonitic monzonites with I-type characteristic, the Sisdağı pluton, NE Turkey: magmatic response to continental lithospheric thinning. Journal of Asian Earth Sciences, 51, 45-62.

Karslı, O., Dokuz, A., Kandemir, R., 2017. Zircon Lu$\mathrm{Hf}$ isotope systematics and $\mathrm{U}-\mathrm{Pb}$ geochronology, whole-rock $\mathrm{Sr}-\mathrm{Nd}$ isotopes and geochemistry of the early Jurassic Gokcedere pluton, Sakarya Zone-NE Turkey: a magmatic response to roll-back of the Paleo-Tethyan oceanic lithosphere. Contributions to Mineralogy and Petrology, 172, 31.

Kaygusuz, A. ve Aydınçakır, E. 2009. Mineralogy, Whole-Rock and Sr-Nd Isotope Geochemistry of Mafic Microgranular Enclaves in Cretaceous Dağbaşı Granitoids, Eastern Pontides, NE Turkey: Evidence of Magma Mixing, Mingling, and Chemical Equilibration. Chemie der Erde/Geochemistry, 69, 247-277.

Kaygusuz, A. ve Aydınçakır, E. 2011. Petrogenesis of a Late Cretaceous composite pluton from the eastern Pontides: the Dağbaşı pluton, NE Turkey. Neues Jahrbuch Für Mineralogie, 188, 3, 211-233.

Kaygusuz, A. ve Şen, C. 2011. Calc-alkaline I-type plutons in the eastern Pontides, NE Turkey: U$\mathrm{Pb}$ zircon ages, geochemical and $\mathrm{Sr}-\mathrm{Nd}$ isotopic compositions. Chemie der Erde Geochemistry, 71, 59-75. 
Kaygusuz, A. ve Öztürk, M. 2015. Geochronology, geochemistry, and petrogenesis of the Eocene Bayburt intrusions, Eastern Pontide, NE Turkey: implications for lithospheric mantle and lower crustal sources in the high-K calc-alkaline magmatism. Journal of Asian Earth Sciences, 108, 97-116.

Kaygusuz, A., Siebel, W., Şen, C. ve Satir, M. 2008. Petrochemistry and petrology of I-type granitoids in an arc setting: the composite Torul pluton, Eastern Pontides, NE Turkey. International Journal of Earth Sciences, 97, 739764.

Kaygusuz, A., Chen, B., Aslan, Z., Siebel, W. ve Şen, C. 2009. U-Pb zircon SHRIMP ages, geochemical and $\mathrm{Sr}-\mathrm{Nd}$ isotopic compositions of the Early Cretaceous I-type Sarısman pluton, Eastern Pontides, NE Turkey. Turkish Journal of Earth Sciences, 18, 549-581.

Kaygusuz, A., Siebel, W., İlbeyli, N., Arslan, M., Satır, M. ve Şen, C. 2010. Insight into magma genesis at convergent plate margins - a case study from the eastern Pontides (NE Turkey). Neues Jahrbuch Für Mineralogie, 187, 3, 265-287.

Kaygusuz, A., Arslan, M., Siebel, W. ve Şen, C. 2011. Geochemical and $\mathrm{Sr}-\mathrm{Nd}$ isotopic characteristics of post-collisional calc-alkaline volcanics in the eastern Pontides (NE Turkey). Turkish Journal of Earth Sciences, 20, 137-159.

Kaygusuz, A., Arslan, M., Siebel, W., Sipahi, F. ve İlbeyli, N. 2012. Geochronological evidence and tectonic significance of Carboniferous magmatism in the southwest Trabzon area, eastern Pontides. Turkey, International Geology Review, 54, 15, 1776-1800.

Kaygusuz, A,. Sipahi, F,. İlbeyli, N,. Arslan, M,. Chen, B, ve Aydınçakır, E. 2013. Petrogenesis of the Late Cretaceous Turnagöl intrusion in the eastern Pontides: Implications for magma genesis in the arc setting. Geoscience Frontiers, 4, 423-438.

Kaygusuz, A., Arslan, M., Wolfgang, S., Sipahi, F., İlbeyli, N. ve Temizel, İ. 2014. LA-ICP MS zircon dating, whole-rock and $\mathrm{Sr}-\mathrm{Nd}-\mathrm{Pb}-\mathrm{O}$ isotope geochemistry of the Camiboğazı pluton, Eastern Pontides, NE Turkey: implications for lithospheric mantle and lower crustal sources in arc-related I-type magmatism. Lithos, 192-195, 271-290.

Kaygusuz, A., Arslan, M., Sipahi, F. ve Temizel, İ. 2016. U-Pb zircon chronology and petrogenesis of Carboniferous plutons in the northern part of the Eastern Pontides, NE Turkey: Constraints for Paleozoic magmatism and geodynamic evolution. Gondwana Research, 39, 327-346.
Köksal, S., Toksoy-Köksal, F., Göncüoğlu, M.C., Möller, A., Gerdes, A. ve Frei, D. 2013. Crustal source of the Late Cretaceous Satansar1 monzonite stock (central Anatolia-Turkey) and its significance for the Alpine geodynamic evolution. Journal of Geodynamics, 65, 82-93.

Lameyre, J. ve Bonin, B., 1991. Granites in the main plutonic series. In: Didier, J., Barbarin, B. (Eds), Enclaves and Granite Petrology. Amsterdam, Elsevier, 3-17.

Le Maitre, R.W., Streckeisen, A., Zanettin, B., Le Bas, M.J., Bonin, B., Bateman, P., Bellieni, G., Dudek, A., Efremova, S., Keller, J., Lamere, J., Sabine, P.A., Schmid, R., Sorensen, H. ve Woolley, A.R. 2002. Igneous Rocks: A Classification and Glossary of Terms, Recommendations of the International Union of Geological Sciences, Subcommission of the Systematics of Igneous Rocks. Cambridge University Press., 236p.

Li, X.H., Li, W.X., Li, Z.X., Lo, C.H., Wang, J., Ye, M.F. ve Yang, Y.H. 2009. Amalgamation between the Yangtze and Cathaysia Blocks in South China: constraints from SHRIMP U-Pb zircon ages, geochemistry and $\mathrm{Nd}-\mathrm{Hf}$ isotopes of the Shuangxiwu volcanic rocks. Precambrian Research, 174, 117-128.

Liu, L., Qiu, J.S., Zhao, J.L. ve Yang, Z.L. 2014. Geochronological, geochemical, and $\mathrm{Sr}-\mathrm{Nd}-\mathrm{Hf}$ isotopic characteristics of Cretaceous monzonitic plutons in western Zhejiang Province, Southeast China: new insights into the petrogenesis of intermediate rocks. Lithos, 196197, 242-260.

Maniar, P.D. ve Piccoli, P.M. 1989. Tectonic discrimination of granitoids. Geological Society of America Bulletin, 101, 635-643.

Middlemost, E.A.K. 1994. Naming materials in the magma/igneous rock system. Earth Science Reviews 37, 215-224.

Miyashiro, A. 1978. Nature of alkalic volcanic rock series. Contributions to Mineralogy and Petrology 66, 91-104.

Morimoto, M., Fabries, J., Ferguson, A.K., Ginzburg, I.V., Ross, M., Seifert, F.A., Zussman, J., Aoki, K. ve Gottardi, G. 1988. Nomenclature of pyroxenes. Mineralogical Magazine, 52, 535550.

MTA, 2002. 1/500.000 ölçekli Türkiye Jeoloji Haritası, Samsun ve Trabzon Paftaları, Maden Tetkik ve Arama Genel Müdürlüğü, Ankara.

Okay, A.İ. ve Şahintürk, Ö. 1997. Geology of the Eastern Pontides. In: Robinson, A.G. (ed.), Regional and Petroleum Geology of the Black 
Sea and Surrounding Region. American Association of Petroleum Geologists Memoir, 68, 291-311.

Okay, A.İ. ve Tüysüz, O. 1999. Tethyan sutures of northern Turkey, In: Durand, B., Jolivet, L., Hovarth, F., Séranne, M. (eds), The Mediterranean Basins: Tertiary Extension within the Alpine Orogen Tethyan Sutures of Northern Turkey. Geological Society London. Special Publications, 156, 475-515.

Okay, A.İ., Sunal, G., Sherlock, S., Altıner, D., Tüysüz, O., Kylander-Clark, A.R.C. ve Aygül, M. 2013. Early Cretaceous sedimentation and orogeny on the active margin of Eurasia: Southern Central Pontides, Turkey. Tectonics, $32,1247-1271$.

Patiño Douce, A.E. ve Beard, J.S. 1996. Effects of P, f $\left(\mathrm{O}_{2}\right)$ and $\mathrm{Mg} / \mathrm{Fe}$ Ratio on Dehydration Melting of Model Metagreywackes. Journal of Petrology, 37, 999-1024.

Pearce, J.A. 1983. The Role of Sub-Continental Lithosphere in Magma Genesis at Destructive Plate Margins. In: Continental Basalts and Mantle Xenoliths, (eds): Hawkesworth, C.J., Norry, M.J., Shiva Publishing, Cheshire, 230249.

Pearce, J.A, Haris, N.B.W. ve Tindle, A.G. 1984. Trace element discrimination diagrams for the tectonic interpretation of granitic rocks. Journal of Petrology, 25, 956-983.

Pearce, J.A., Bender, J.F., De Long, S.E., Kidd, W.S.F., Low, P.J., Güner, Y., Şaroğlu, F., Y1lmaz, Y., Moorbath, S. ve Mitchell, J.J. 1990. Genesis of collision volcanism in eastern Anatolia Turkey. Journal of Volcanology and Geothermal Research, 44, 189-229.

Rapp, R.P. ve Watson, E.B. 1995. Dehydration Melting of Metabasalt at 8-32 kbar: Implications for Continental Growth and Crust-Mantle Recycling. Journal of Petrology, 36, 891-931.

Roberts, M.P. ve Clemens, J.D. 1993. Origin of HighPotassium, Calcalkaline, I-Type Granitoids. Geology, 21, 825-828.

Robinson, A.G., Banks, C.J., Rutherford, M.M. ve Hirst, J.P.P. 1995. Stratigraphic and structural development of the eastern Pontides, Turkey. Journal of the Geological Society, London, 152, 861-872.

Singh, J. ve Johannes, W. 1996. Dehydration Melting of Tonalites: Part II. Composition of Melts and Solids. Contributions to Mineralogy and Petrology, 125, 26-44.
Sipahi, F., 2017. Kalınçam (Tonya-Trabzon, KD Türkiye) Yöresi Geç Kretase Yaşlı Volkanitlerin Jeokimyası ve Petrojenezi. Gmüşhane Fen Bilimleri Enstitüsü Dergisi, 7 (2), 102-127.

Sipahi, F., Akpınar, İ., Saydam Eker, Ç., Kaygusuz, A., Vural, A., Y1lmaz, M., 2017. Formation of the Eğrikar (Gümüşhane) $\mathrm{Fe}-\mathrm{Cu}$ skarn type mineralization in NE Turkey: U-Pb zircon age, lithogeochemistry, mineral chemistry, fluid inclusion, and O-H-C-S isotopic compositions. Journal of Geochemical Exploration, 182 (Part A), 32-52

Sipahi, F., ve Sadıklar, M.B., 2014. Geochemistry of dacitic volcanics in the eastern pontides (NE Turkey). Geochemistry International, 4, 329349.

Sipahi, F., Kaygusuz, A., Saydam Eker, Ç., Vural, A., Akpinar, İ., 2018. Late Cretaceous arc igneous activity: the Eğrikar Monzogranite example. International Geology Review, 60 (3), 382-400.

Sipahi, F., Sadıklar, M.B., Şen, C., 2014. The Geochemical and $\mathrm{Sr} \mathrm{Nd}$ isotopic Characteristics of Murgul Artvin Volcanics in the Eastern Black Sea Region NE Turkey. Chemie Der Erde/Geochemistry, 74 (3), 331-342.

Stevens, G., Clemens, J.D. ve Droop, G.T.R. 1997. Melt Production during Granulite Facies Anatexis: Experimental Data from 'Primitive' Metasedimentary Protoliths. Contributions to Mineralogy and Petrology, 128, 352-370.

Streickeisen, A. 1976. To Each Plutonic Rock its Proper Name. Earth Science Review, 12, 1-33.

Sun, S. ve McDonough, W.F. 1989. Chemical and isotopic systematics of oceanic basalt: Implications for mantle composition and processes. In: A.D. Saunders, M.J. Norry, (eds.), Magmatism in the Ocean Basins, Geological Society of London. Special Publication, 42, 313-345.

Şengör, A.M.C. ve Y1lmaz Y. 1981. Tethyan Evolution of Turkey: A Plate Tectonic Approach. Tectonophysics, 75, 181-241.

Şengör, A.M.C., Özeren, S., Genç, T. ve Zor, E. 2003. East Anatolian high plateau as a mantle supported, north-south shortened domal structure. Geophysical Research Letters, 30(24), 8045 .

Taylor, S.R. ve McLennan, S.M. 1985. The Continental Crust, Its Composition and Evolution. Blackwell, Oxford, 312.

Temizel, İ. 2014. Petrochemical evidence of magma mingling and mixing in the Tertiary 
monzogabbroic stocks around the Bafra (Samsun) area in Turkey: implications of coeval mafic and felsic magma interactions. Mineralogy and Petrology, 108, 353-370.

Temizel, İ., Arslan, M., Yücel, C., Abdioğlu, E. ve Ruffet, G. 2016. Geochronology and geochemistry of Eocene-aged volcanic rocks around the Bafra (Samsun, N Turkey) area: Constraints for the interaction of lithospheric mantle and crustal melts. Lithos, 258-259, 92114.

Temizel, İ., Abdioğlu Yazar E., Arslan, M., Kaygusuz, A. ve Aslan, Z. 2018. Mineral chemistry, whole-rock geochemistry and petrology of Eocene I-type shoshonitic plutons in the Gölköy area (Ordu, NE Turkey). Bulletin of the Mineral Research and Exploration, 157, 121-152.

Thirlwall, M.F., Smith, T.E., Graham, A.M., Theodorou, N., Hollings, P., Davidson, J.P. Arculus, R.J. 1994. High field strength element anomalies in arc lavas; source or process?. Journal of Petrology, 35, 3, 819-838.

Thiéblemont D., Tégyey M. 1994. Une discrimination géochimique des roches différenciées témoin de la diversité d'origine et de situation tectonique des magmas calcio-alcalins. Comptes Rendus de l'Académie des Sciences, 319, 87-94.

Topuz, G. 2002. Retrograde P-T path of anatectic migmatites from the Pulur Massif, Eastern Pontides, NE Turkey: petrological and microtextural constraints. 1st International Symposium of the Faculty of Mines (ITÜ) on Earth Sciences and Engineering Abstracts, Istanbul, Turkey, $110 \mathrm{p}$.

Topuz, G., Altherr, R., Siebel, W., Schwarz, W.H., Zack, T., Hasözbek, A., Barth, M., Satır, M., Şen, C. 2010. Carboniferous High-Potassium IType Granitoid Magmatism in the Eastern Pontides: The Gümüşhane Pluton (NE Turkey). Lithos, 116, 92-110.

Topuz, G., Çelik, Ö.F., Şengör, A.M.C., Altıntaş, İ. E., Zack, T., Rolland, Y. ve Barth, M. 2013. Jurassic Ophiolite Formation and emplacement as backstop to a subduction-accretion complex in Northeast Turkey, The Refahiye Ophiolite, and relation to the Balkan Ophiolites. American Journal of Science, 313, 1054-1087.

Ustaömer, T. ve Robertson, A.H.F. 1995. PalaeoTethyan tectonic evolution of the north Tethyan margin in the Central Pontides, N. Turkey. In: Geology of the Black Sea region (eds). Erler, A., Ercan, T., Bingöl, E., Örçen, S., MTA/JMO, 24-32.

Ustaömer, T. ve Robertson, A.H.F. 2010. Late Palaeozoic-Early Cenozoic tectonic development of the Eastern Pontides (Artvin area), Turkey: stages of closure of Tethys along the southern margin of Eurasia. In Stephonson, R.A., Kaymakc1, N., Sasson, M., Starostenko, V., Bergerat, F. (eds). Sedimentary Basin Tectonics from the Black Sea and Caucasus to the Arabian Platform. Geological Society, London. Special Publications, 340, 281-327.

Ustaömer, T., Robertson, A.H.F., Ustaömer, P.A., Gerdes, A. ve Peytcheva, I. 2013. Constraints on Variscan and Cimmerian magmatism and metamorphism in the Pontides (Yusufeli-Artvin area), NE Turkey from $\mathrm{U}-\mathrm{Pb}$ dating and granite geochemistry. in Robertson, A.H.F., Parlak, O., Ünlügenç, U.C. (eds). Geological Development of Anatolia and the Easternmost Mediterranean Region. Geological Society, London. Special Publications, 372, 49-74.

Y1lmaz, S. ve Boztuğ, D. 1996. Space and time relations of three plutonic phases in the Eastern Pontides, Turkey. International Geology Review, 38, 10, 935-956.

Yılmaz, Y., Tüysüz, O., Yiğitbaş, E., Genç, Ş.C. ve Şengör, A.M.C. 1997. Geology and tectonics of the Pontides. in Robinson, A.G. (eds.), Regional and Petroleum Geology of the Black Sea and Surrounding Region. American Association of Petroleum Geologists Memoir, 68, 183-226.

Yücel, C., Arslan, M., Temizel, İ., Abdioğlu, E. ve Ruffet, G. 2017. Evolution of K-rich magmas derived from a net veined lithospheric mantle in an ongoing extensional setting: Geochronology and geochemistry of Eocene and Miocene volcanic rocks from Eastern Pontides (Turkey). Gondwana Research, 45, 65-86. 